\title{
انعكاس تقويم اداء الادارات على تحسين جودة العمل المؤسسي
}

$$
\text { أ.م.د. عبد الناصر علك حافظ/وزارة التعليم العالي والبحث العلمي }
$$

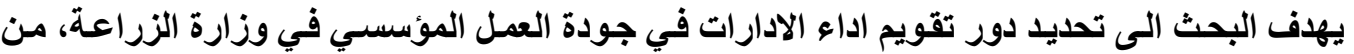

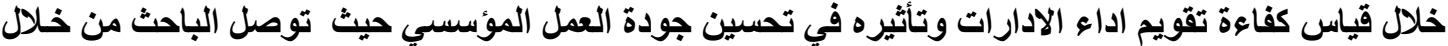

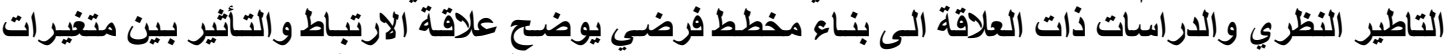

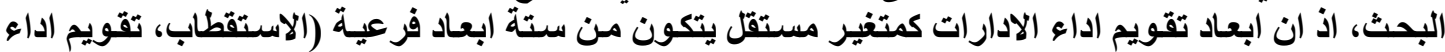

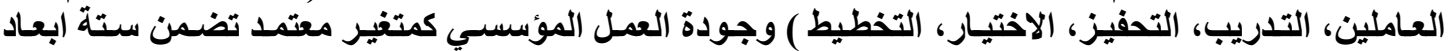

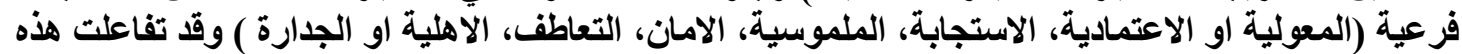

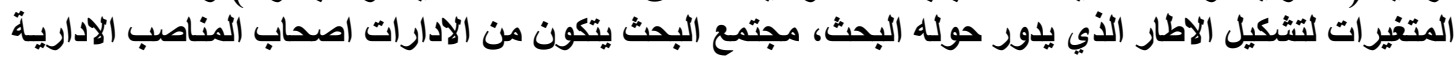

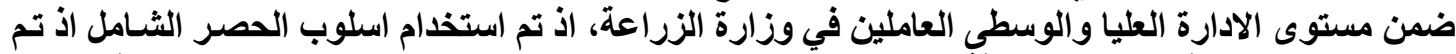

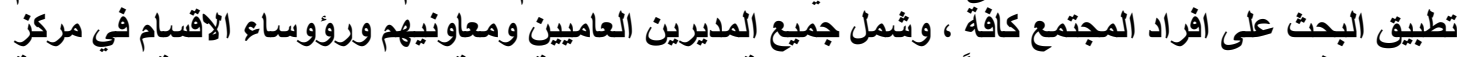

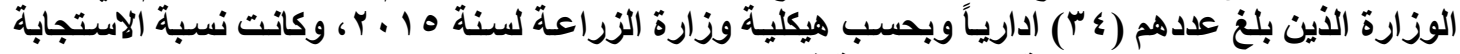

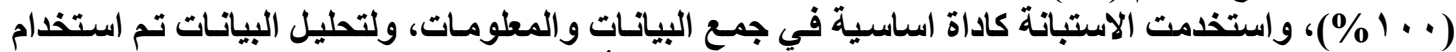

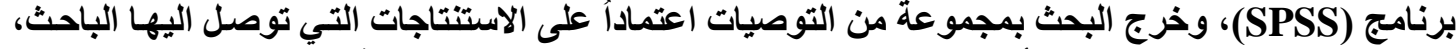

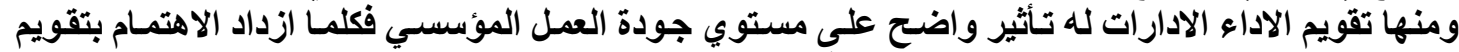

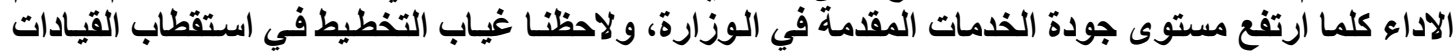

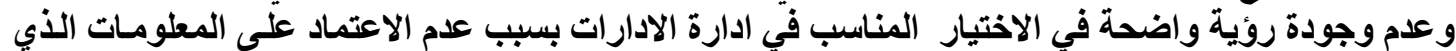

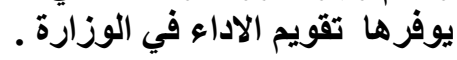

المصلحات الرئيسية لابحث/ تقويم الاداء- جودة- جودة العمل المؤسسي- تقويم اداء الادارات

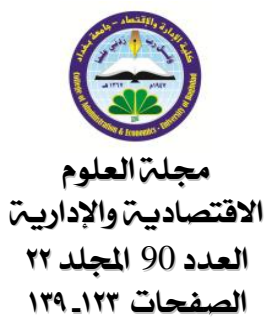


تمثثل الادارات الإدارية إحدى المرتكزات الأساسية في الأداء الوظيفي، اذ قد تمتلكت الموارد المالية الجيدة

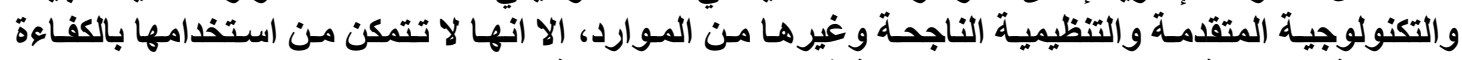

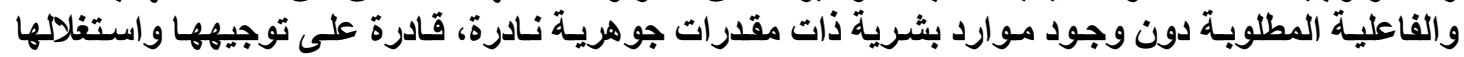

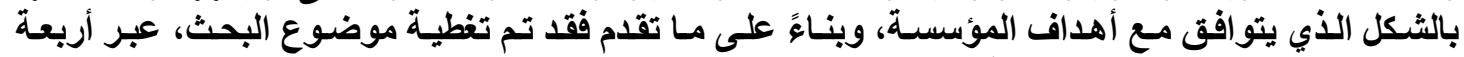

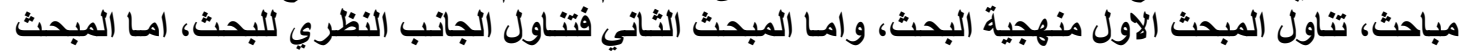

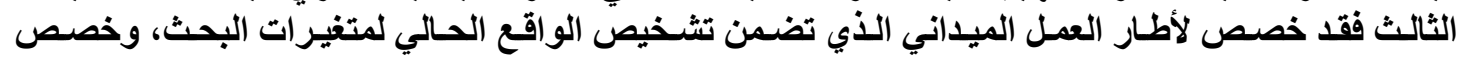
المبحث الرابع لتقديم الأستنتاجات التي تم استنباطها من الأطار النظري والجي الجانب العلمي للبحث، واخيراً توصيات البحث.

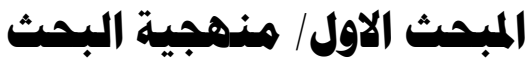

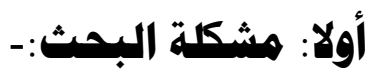

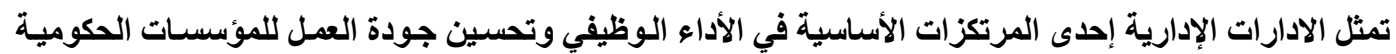

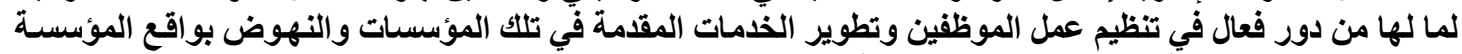

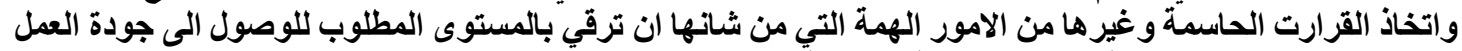

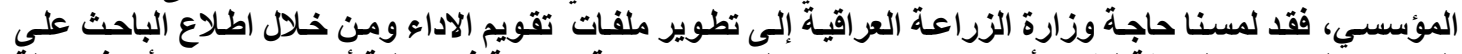

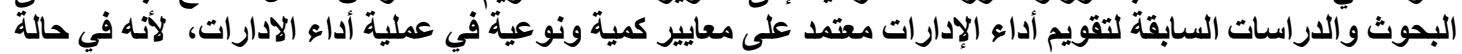

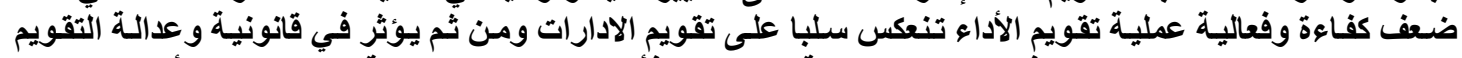

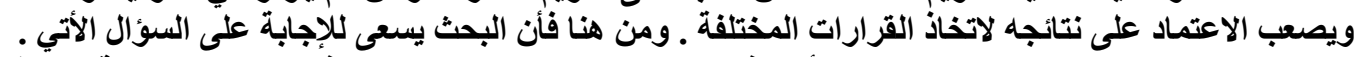

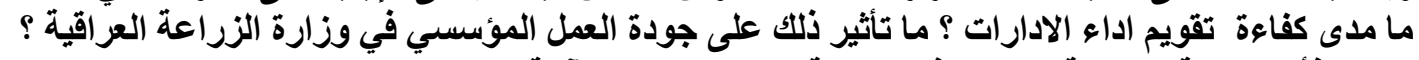

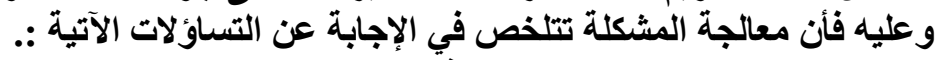

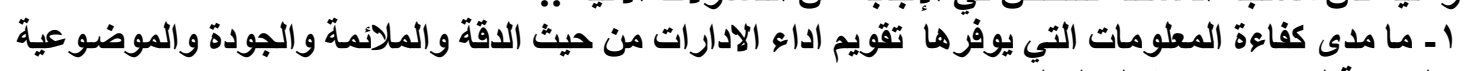
والسرعة لتحسين جودة العمل المطات المؤسيسي.

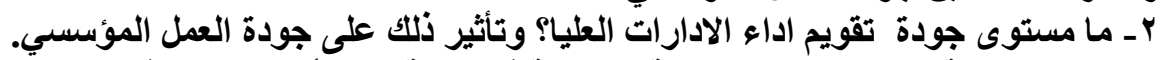

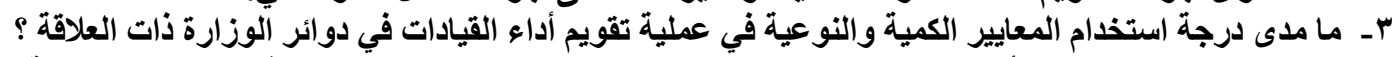

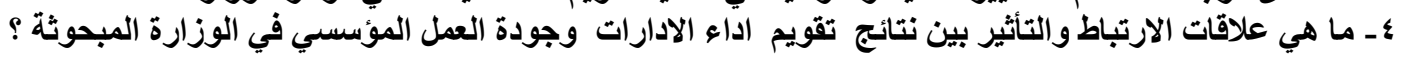

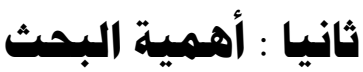

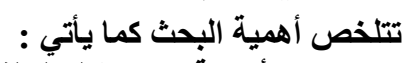

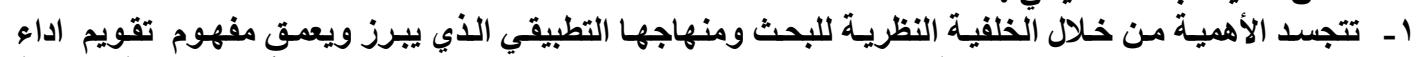

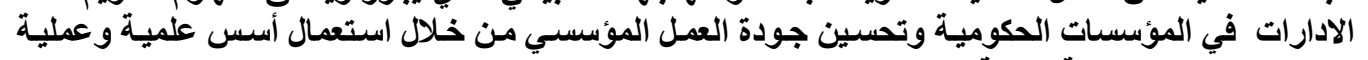

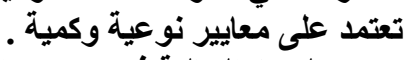

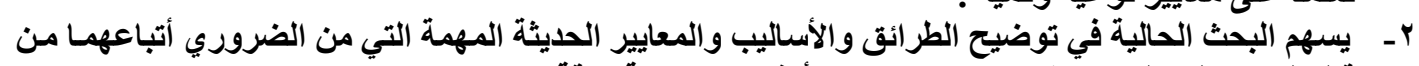

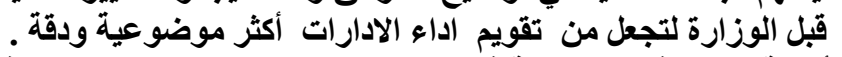

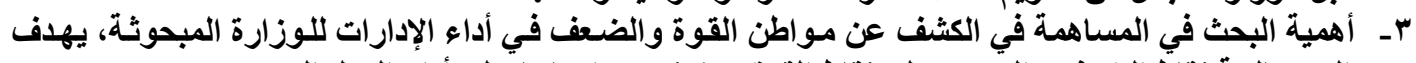

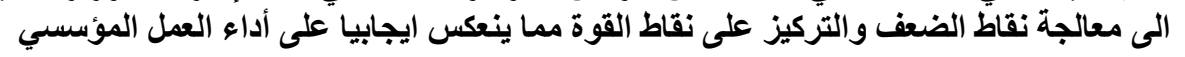

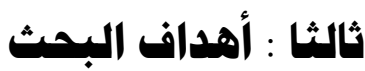

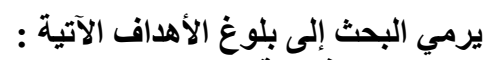

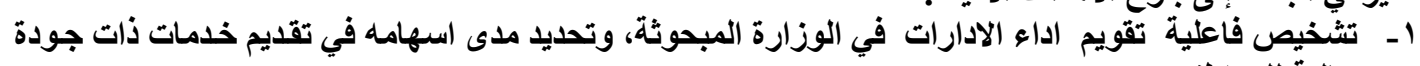
عالية للمواطنين ف فاعلية

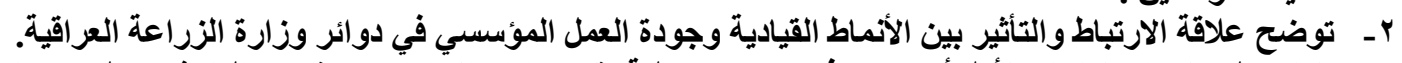

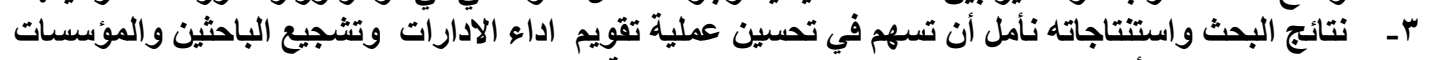

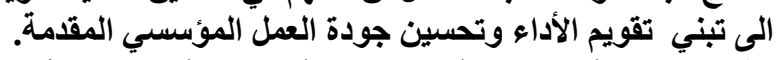

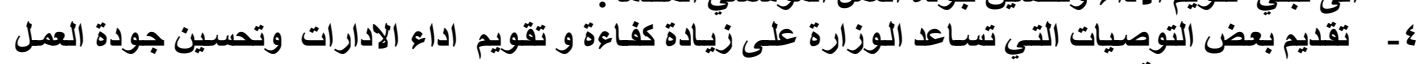

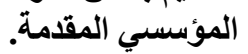




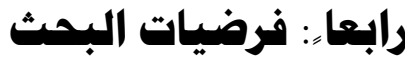

يستثد البحث الحالي الى الفرضيات الاتية لتحقيق الهدافئه:

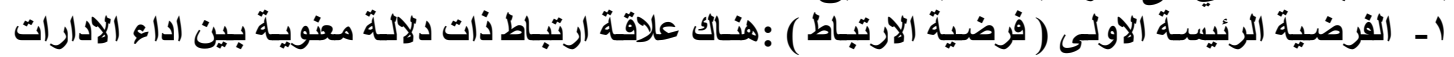

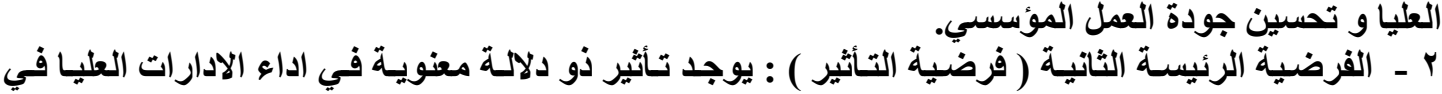

$$
\begin{aligned}
& \text { تحسين جودة العمل المؤسسي }
\end{aligned}
$$

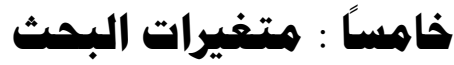

نظرا لاختلاف الكتاب والباحثين على ابعاد تقويم اداء القيادات وعددها ـ ندرج الجدول (1) يوضح اراء الكتاب

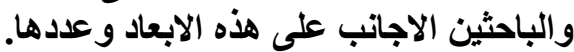

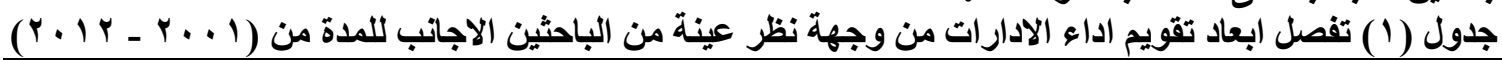

\begin{tabular}{|c|c|c|c|c|c|c|c|}
\hline التخطيط & الاختيار & التحفيز & التدريب & تقويم اداء & الاستقطاب & الابعاد & ت \\
\hline & $*$ & $*$ & $*$ & $*$ & $*$ & Denisi and Griffiin,2001 & 1 \\
\hline$*$ & & $*$ & $*$ & & $*$ & Bohlander and Snell,2004 & $r$ \\
\hline$*$ & $*$ & $*$ & $*$ & $*$ & $*$ & Beardwell and Claydon,2010 & $r$ \\
\hline \multirow[t]{3}{*}{$*$} & * & * & * & $*$ & * & Noe et al . 2011 & $\varepsilon$ \\
\hline & & $*$ & $*$ & $*$ & $*$ & Dessler , 2011 & 0 \\
\hline & $*$ & $*$ & $*$ & $*$ & $*$ & Sani , 2012 & 7 \\
\hline$r$ & $\varepsilon$ & 7 & 7 & ○ & 7 & 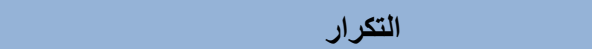 & \\
\hline
\end{tabular}

المصدر : من اعداد الباحث.

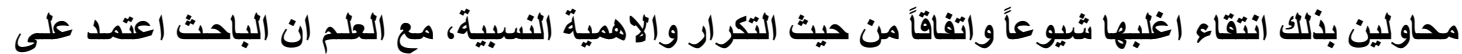

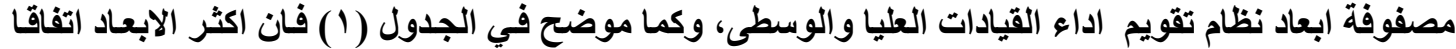

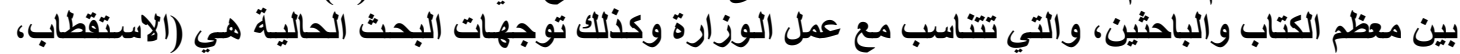

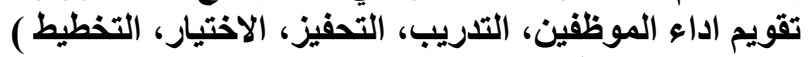

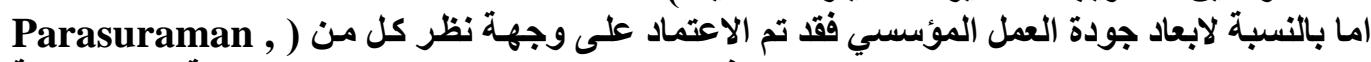
(Zithaml and Berry , 1985 , p41 - 50

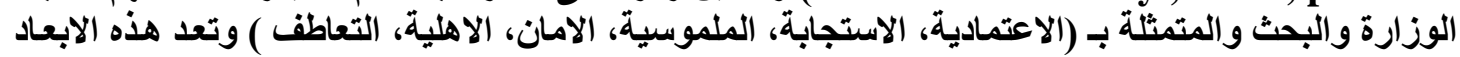

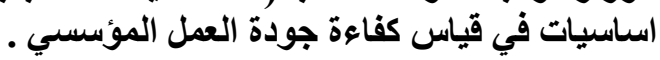

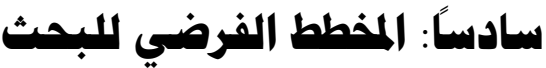

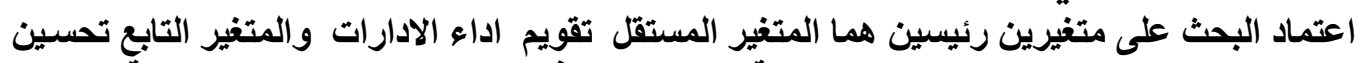

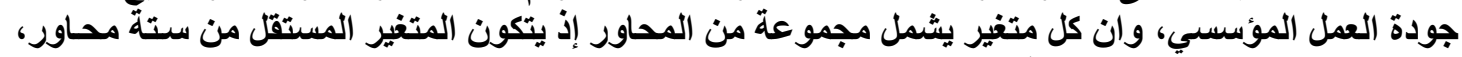
إما المتغير التابع فيتكون من ستة وان إبعاد 


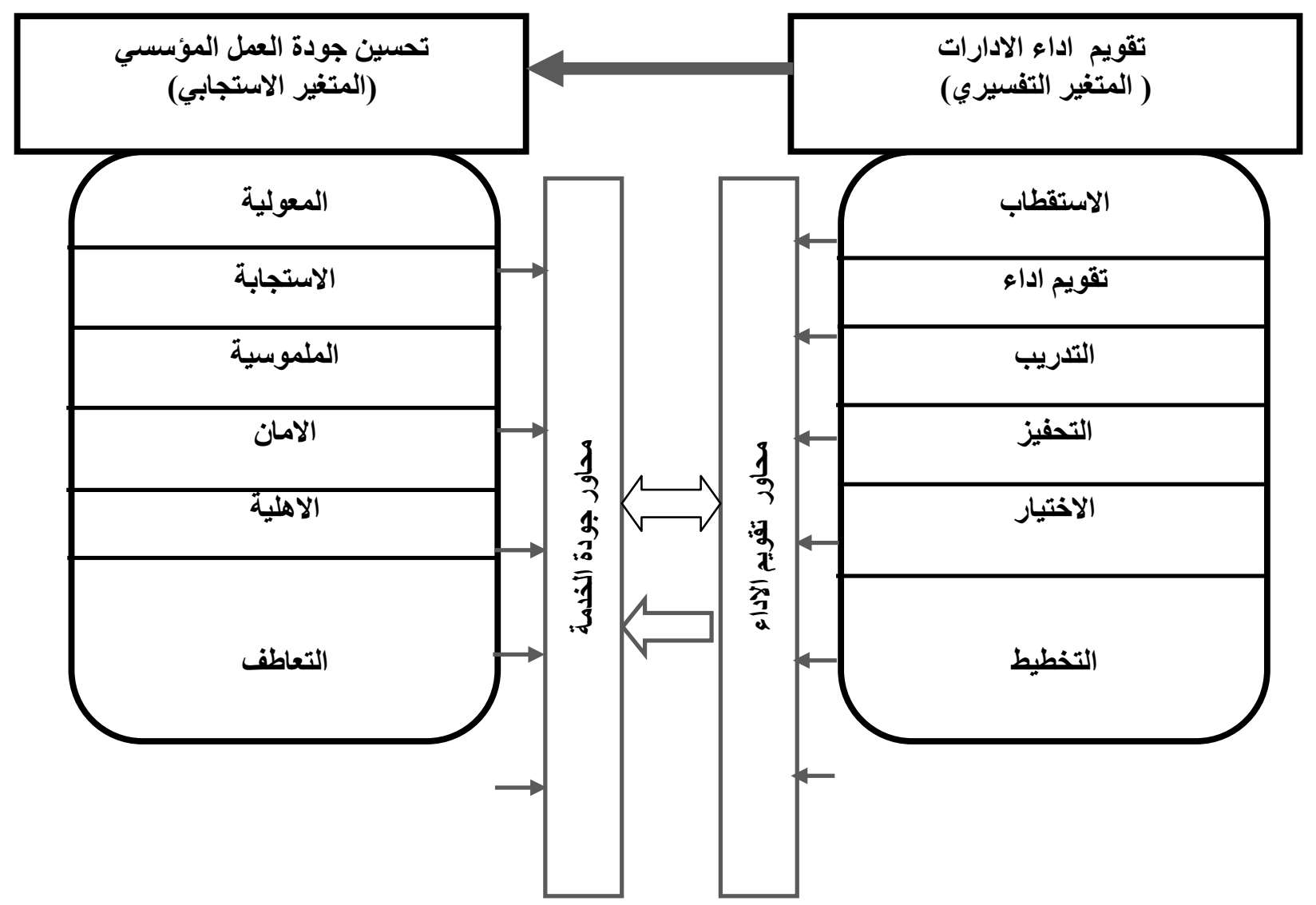

شكل ( 1 ) المخطط الفرضي للبحث

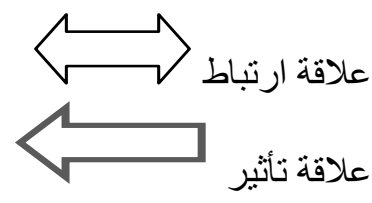

من تصور الباحث اعتماداً على متغيرات البحث وابعادها لإنها 


\section{سابعًا : التعاريف الإجرائية}

\section{إن المتفيرات الرئيسة والفرعية تحتاج إلى تعاريف إجرائية وكما يأتي : المئية}

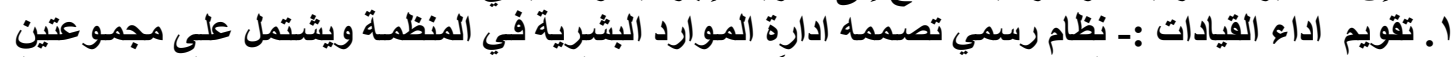

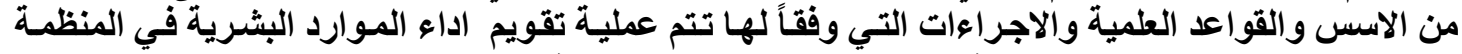

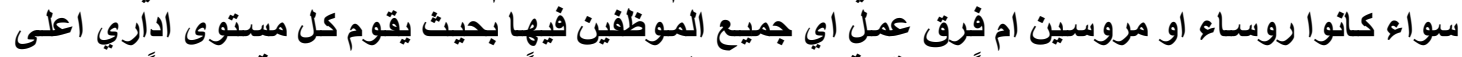

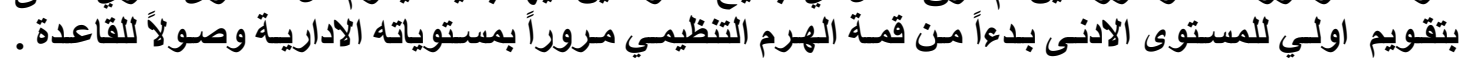

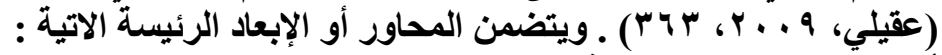

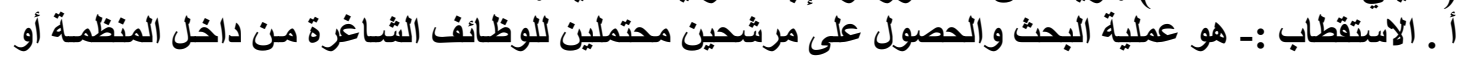

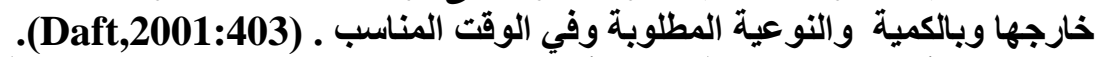

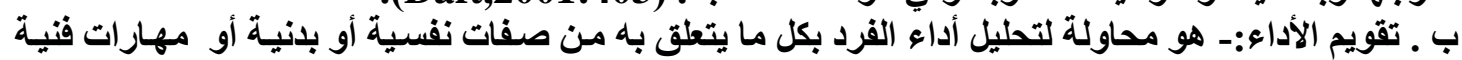

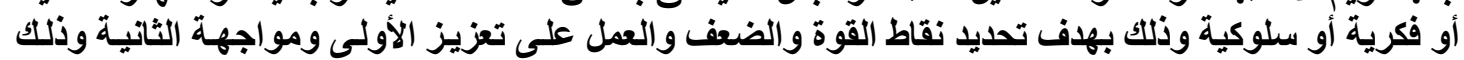

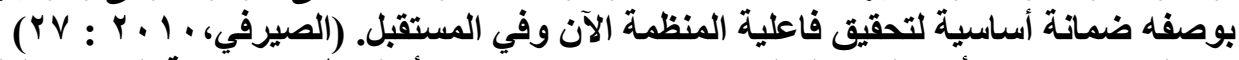

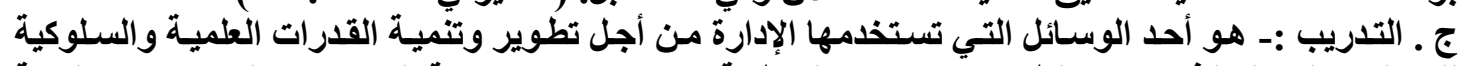

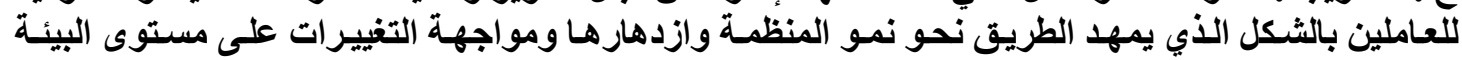

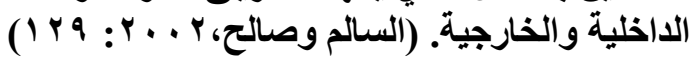

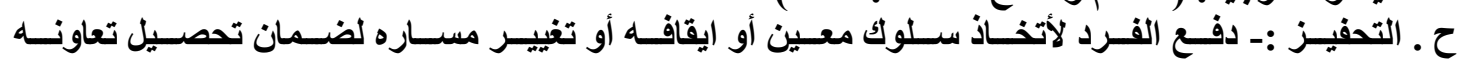

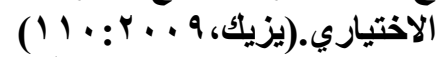

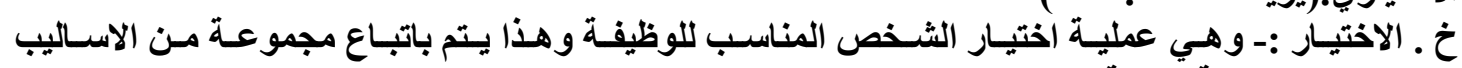

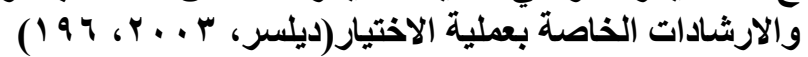

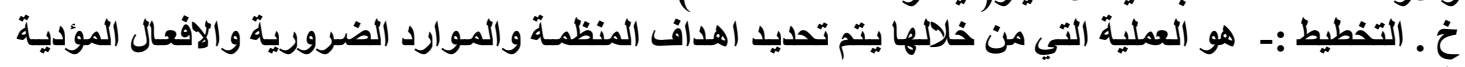

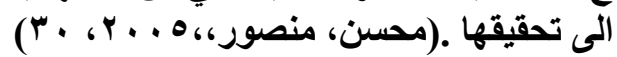

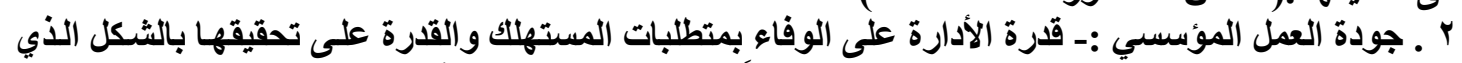

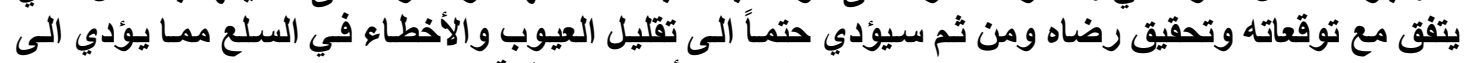

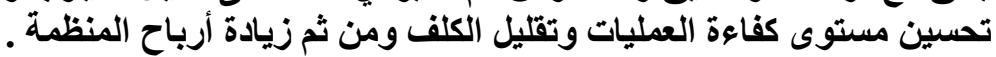

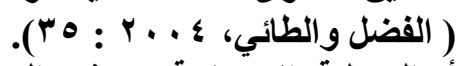

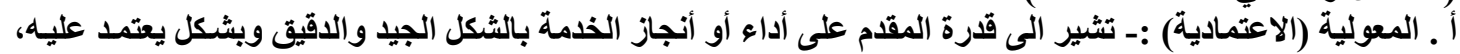

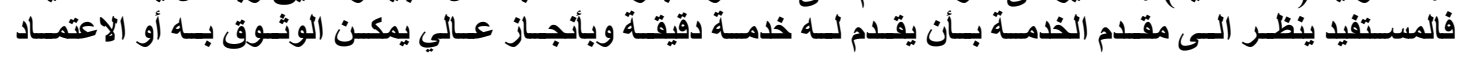

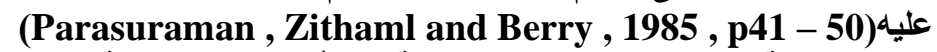

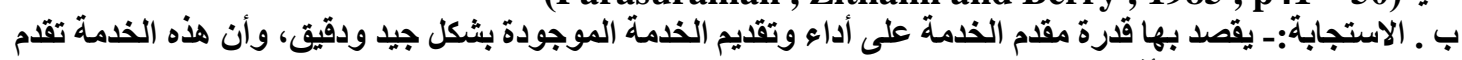

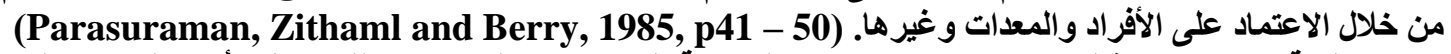

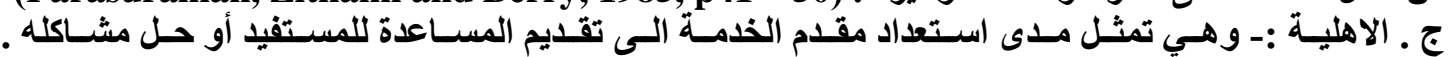

(Parasuraman , Zithaml and Berry , 1985 , p41 - 50)

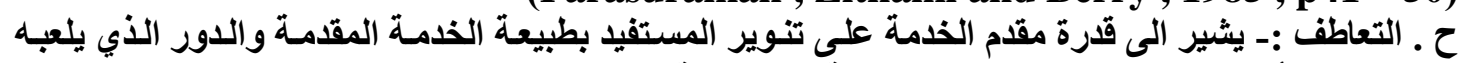

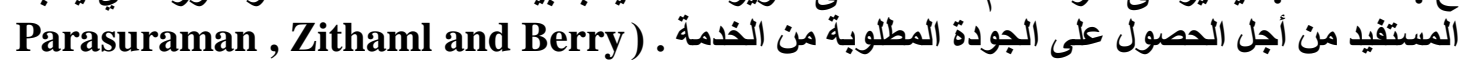
(, 1985, p41 - 50

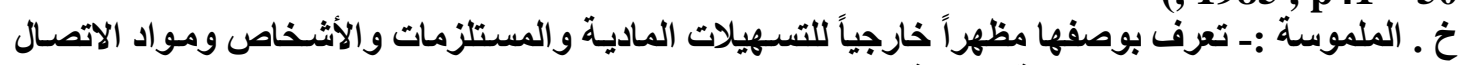

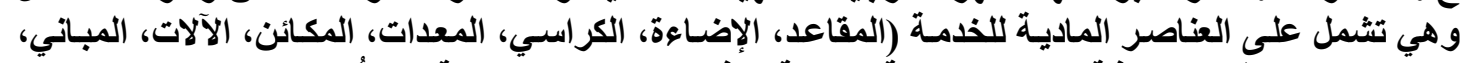

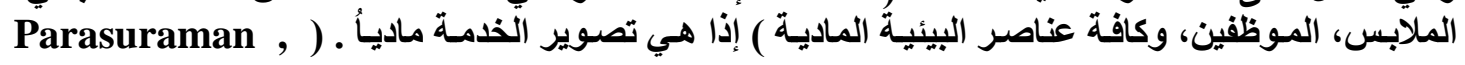

(Zithaml and Berry , 1985 , p41 - 50

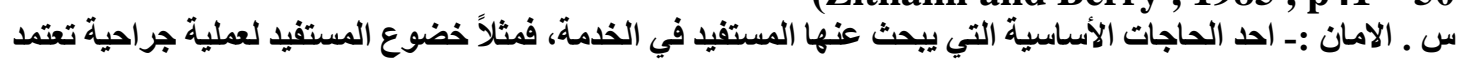

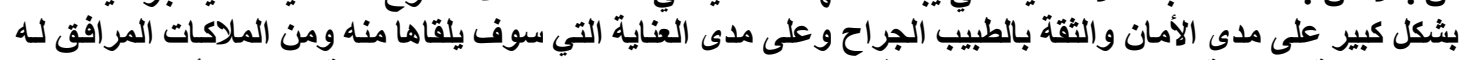

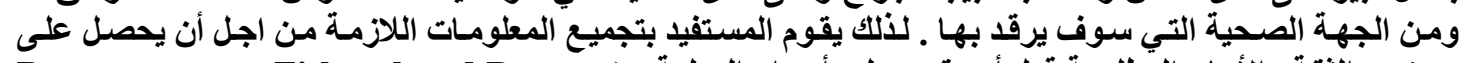

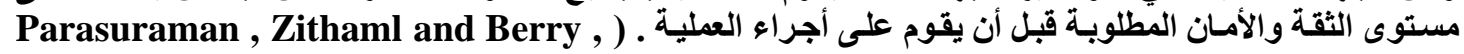

(1985, p41 - 50 


\section{ثاهنًا : أدوات جمع البيانات والمعلوهات}

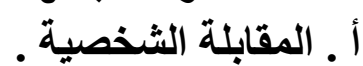

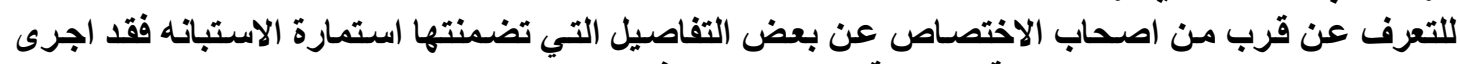

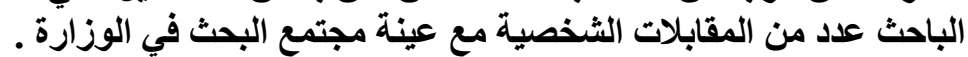

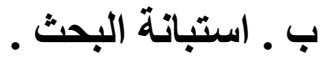

شكلت الاستبانة المصدر الاساس الذي اعتمده الباحث في الحصول على المعلومـات المتعلقة بالجانب

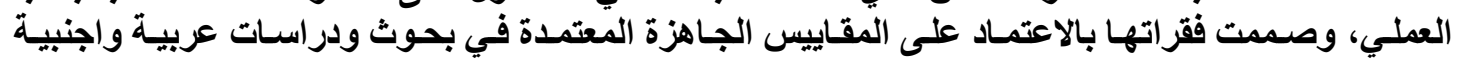

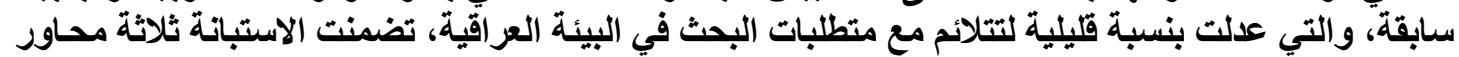

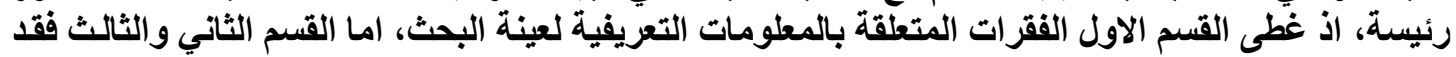

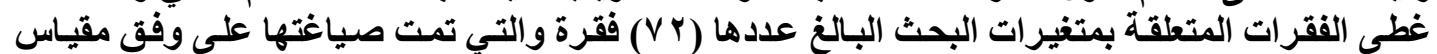

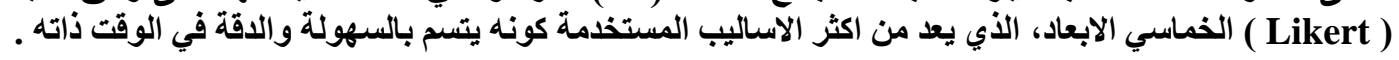

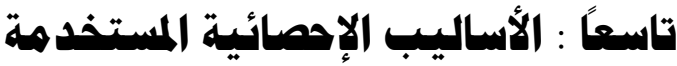

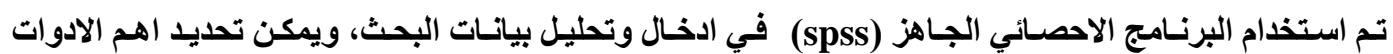

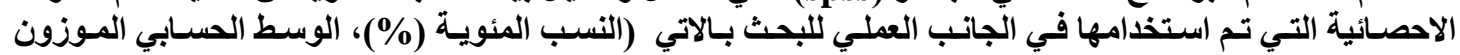

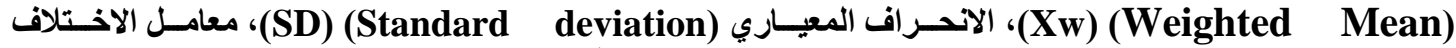
(C) (Coefficient of variation)

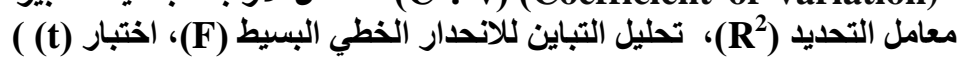

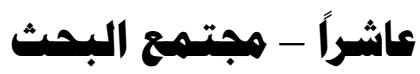

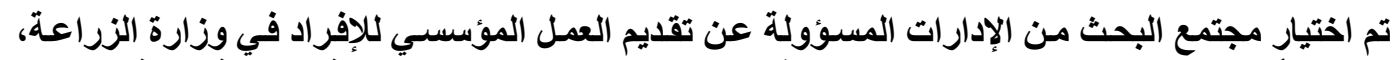

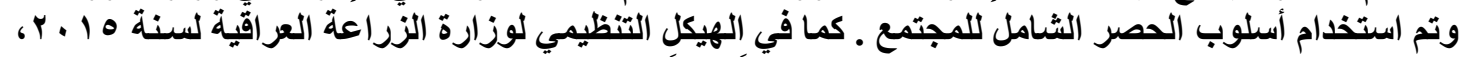

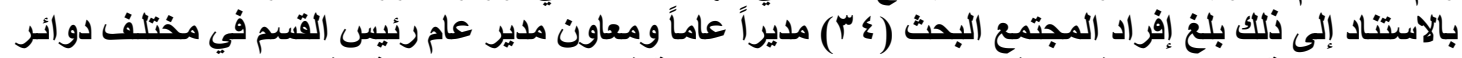

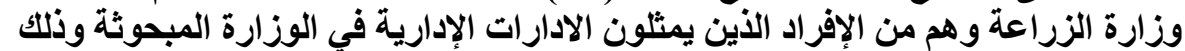

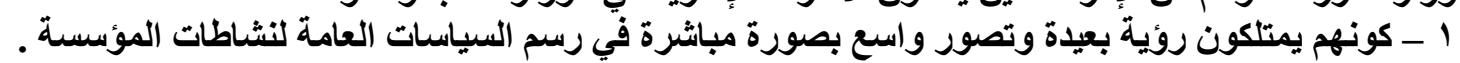

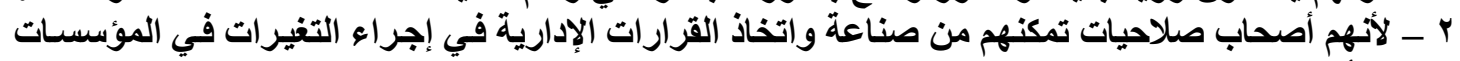

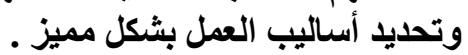

\section{المبحث الثاني : الجانب النظري النئري}

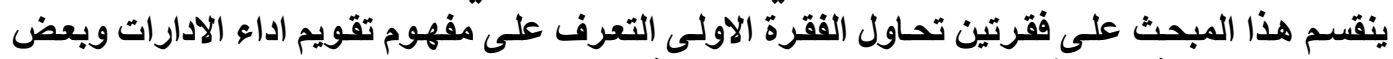

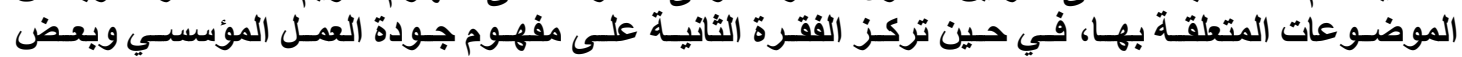

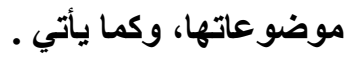

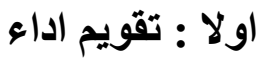

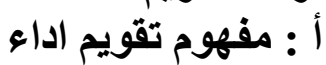

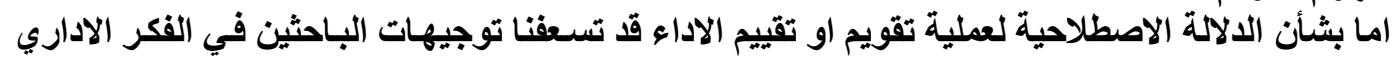

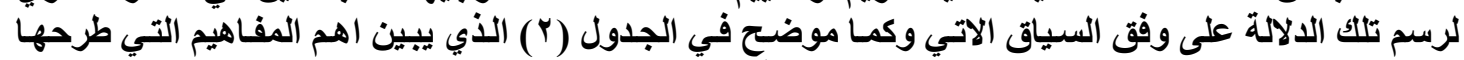

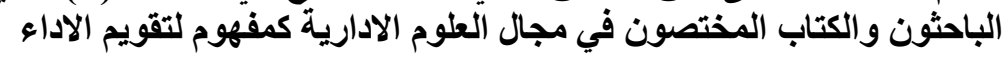


جدول (r) بعض تعاريف تقويم الاداء

\begin{tabular}{|c|c|c|}
\hline الدلالة الاصطلاحية & 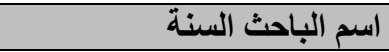 & $ت$ \\
\hline 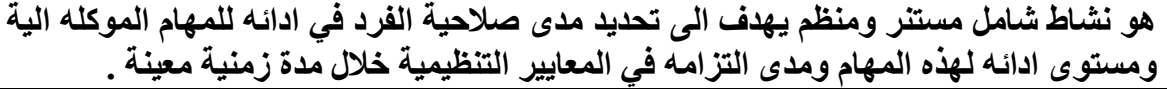 & 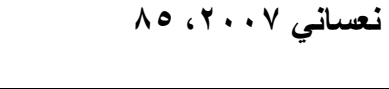 & 1 \\
\hline 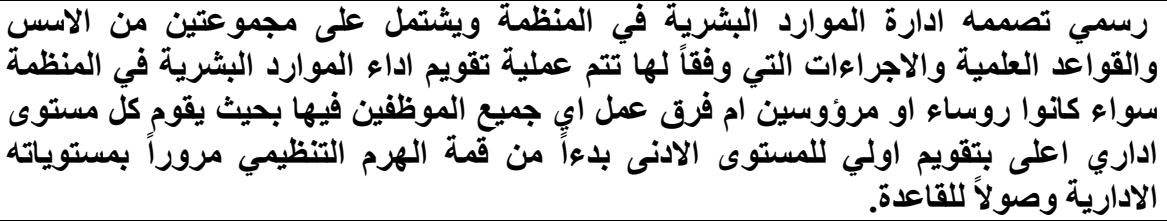 & 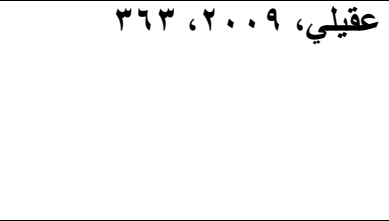 & r \\
\hline عملية تقويم اداء العمل لكل فرد لكي يتم اتخاذ القرارات الموضوعيةّ المرتبطة بالفرد & ৭، Y.. ৭ ‘Jafar etal & $r$ \\
\hline 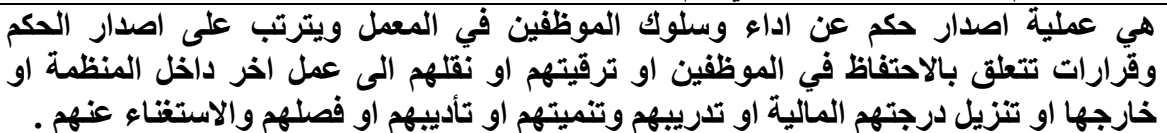 & 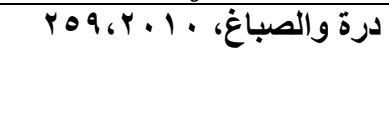 & $\varepsilon$ \\
\hline
\end{tabular}

\section{ب - اهمية تقويم الاداء}

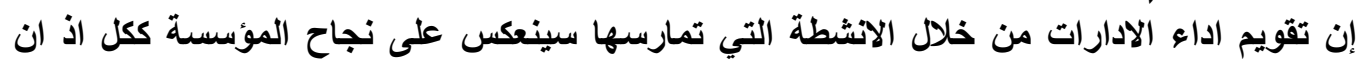

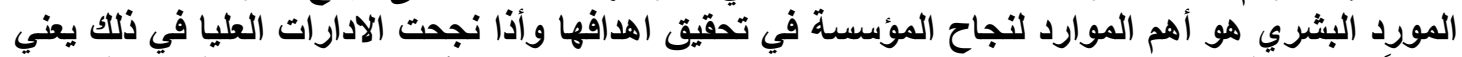

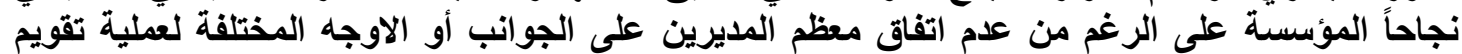

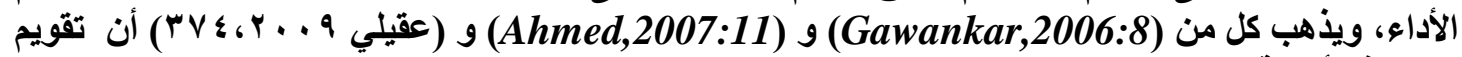

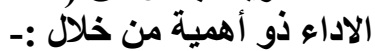

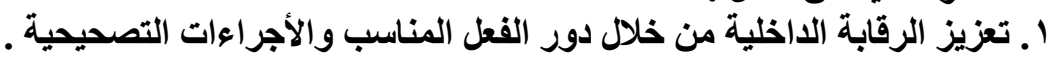

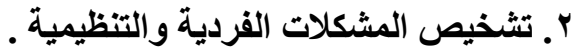

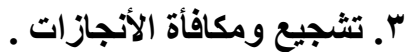

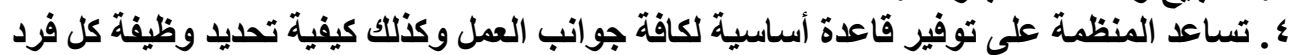

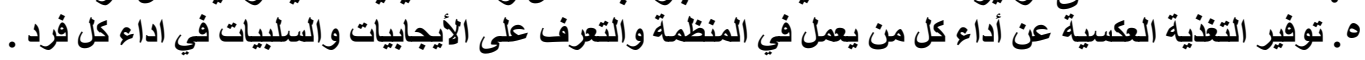

\section{ج - اهداف تقويم الاداء.}

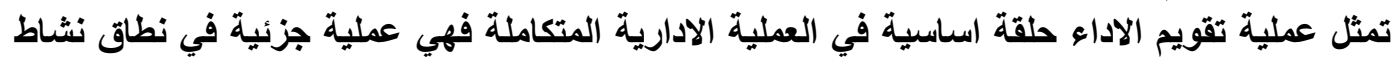

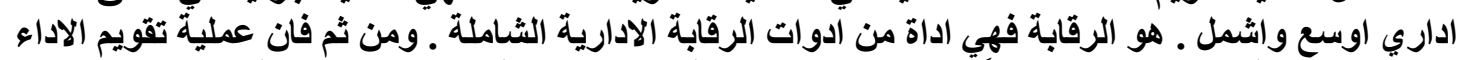

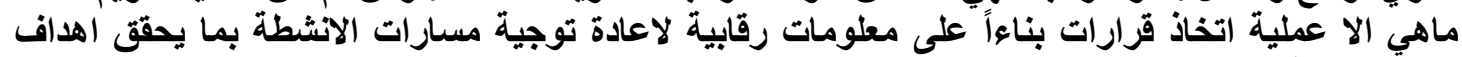

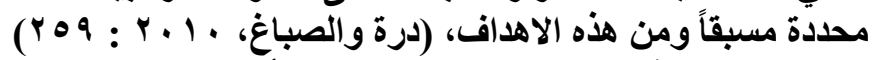

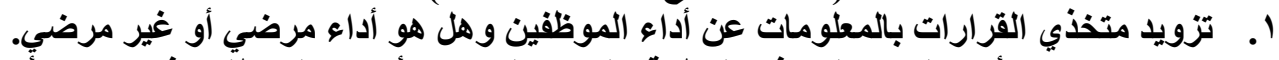

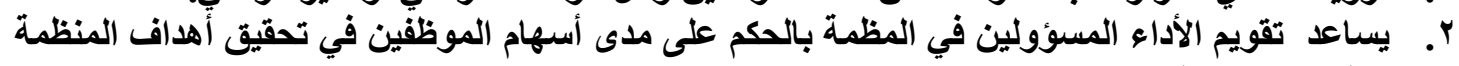

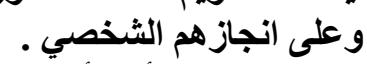

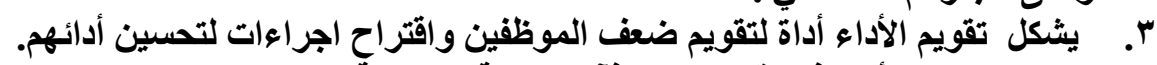

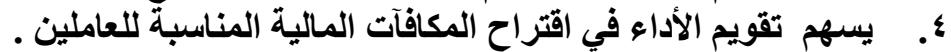

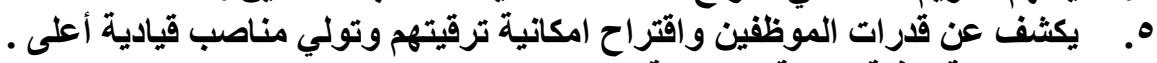
7. . ئد وسيلة تغذية راجعة (العكسية).

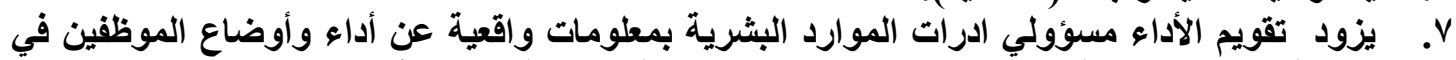

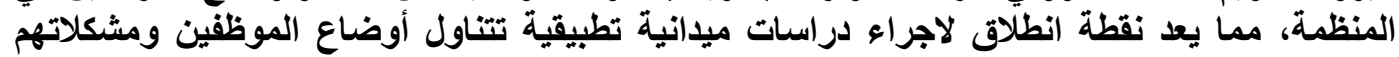

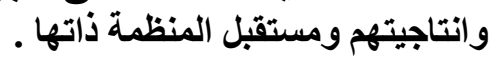




\section{د - نمائص تقويم الاداك}

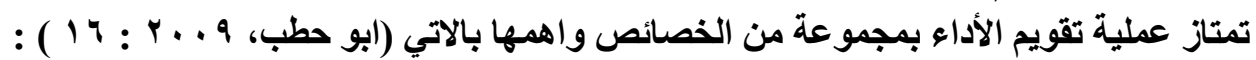

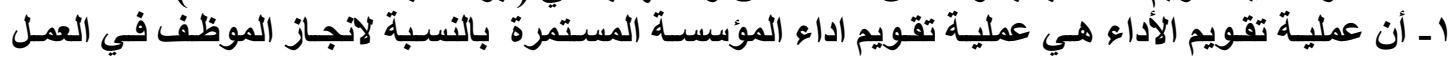

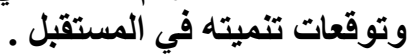

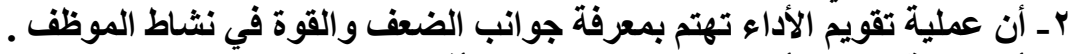

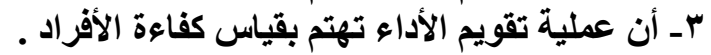

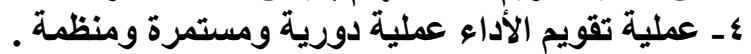
هـ نتائج عملية تقويم الأداء يبنى عليها دورية قرارات وظيفية مختلفة .

\section{هـ - نهوات تقويم الاداء}

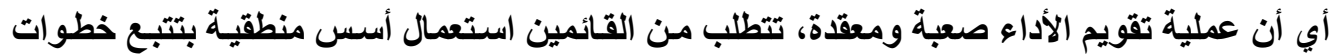

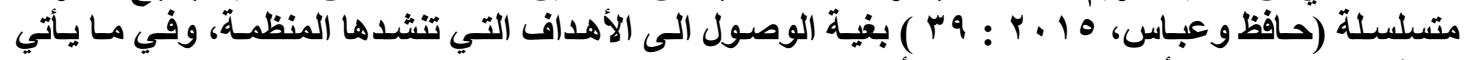

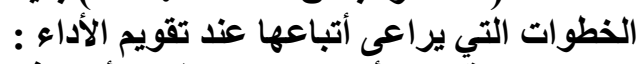

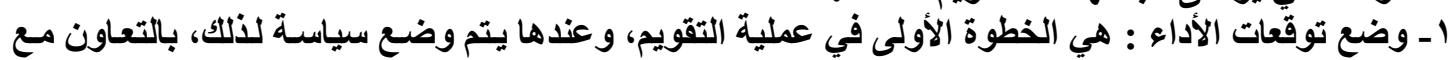

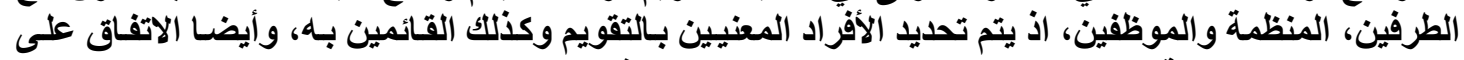

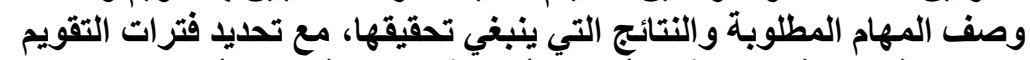

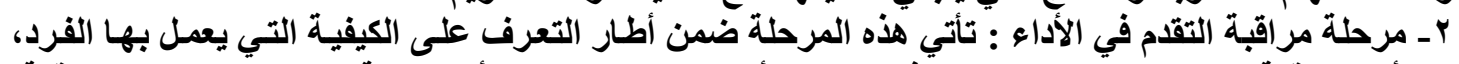

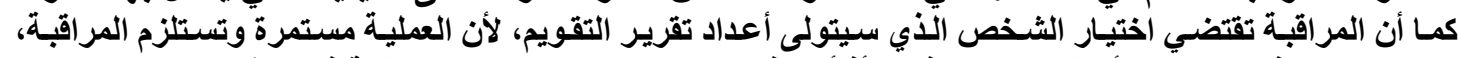

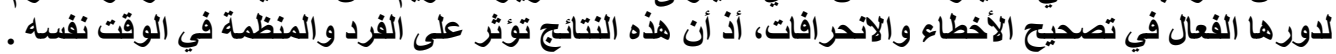

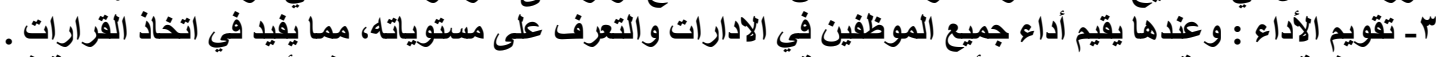

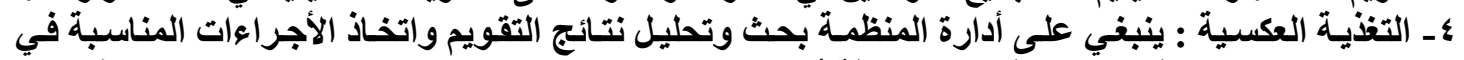

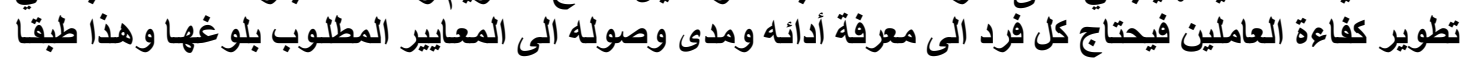

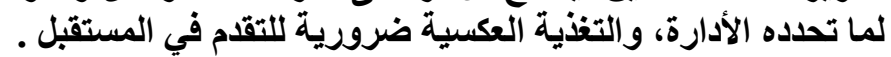

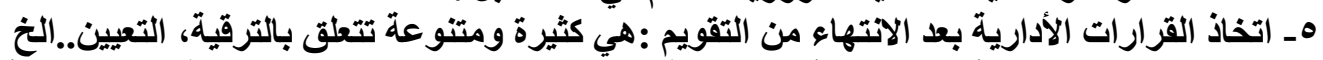

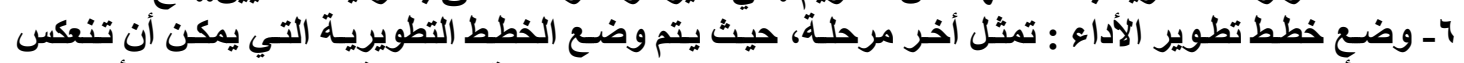

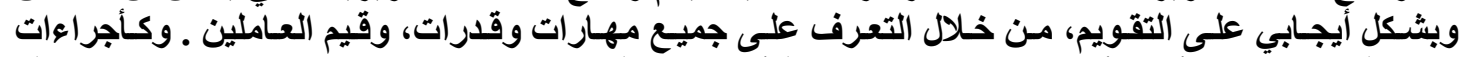

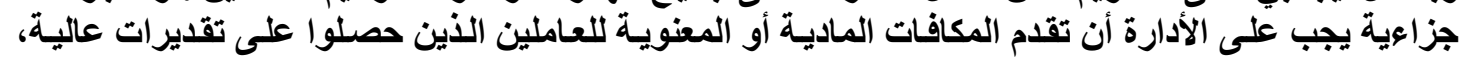

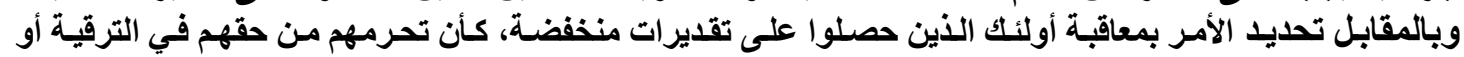

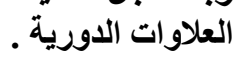

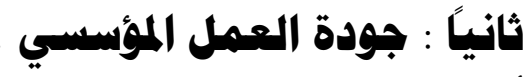

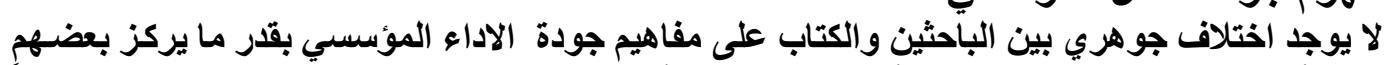

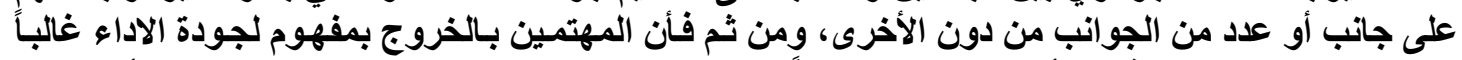

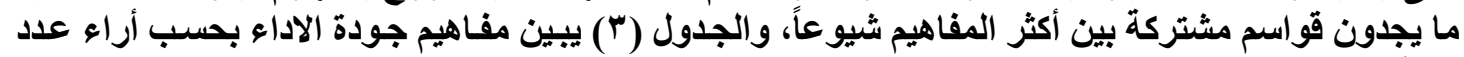

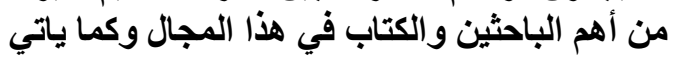




\begin{tabular}{|c|c|c|}
\hline التعريف & الكاتب / السنة / الصفحة & $ت$ \\
\hline تطابق الاداء لتوقعات وتفضيلات الزبائن . & Lezzoin \& Davis , 2003 : 163 & 1 \\
\hline المحدد الرئيس لرضا الزبون أو عدم رضاه . & 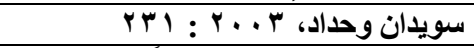 & $r$ \\
\hline 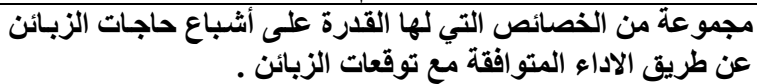 & 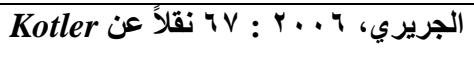 & $r$ \\
\hline 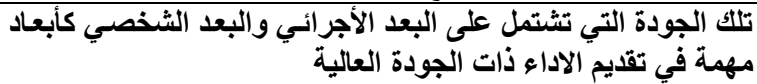 & 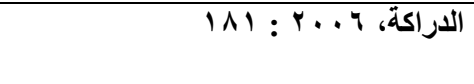 & $\varepsilon$ \\
\hline
\end{tabular}

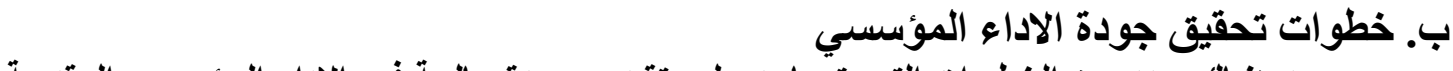

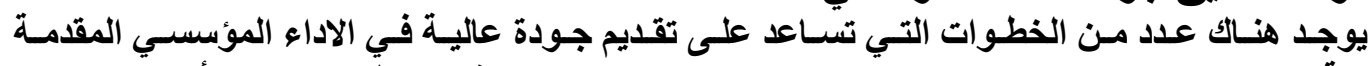

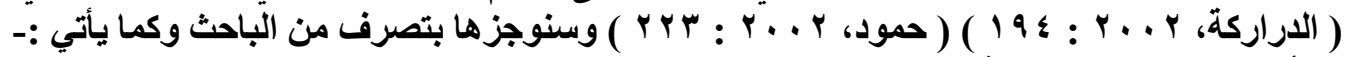

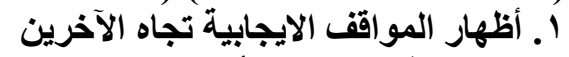

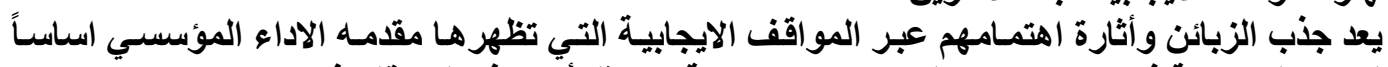

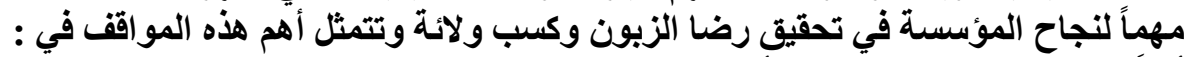

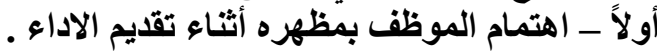

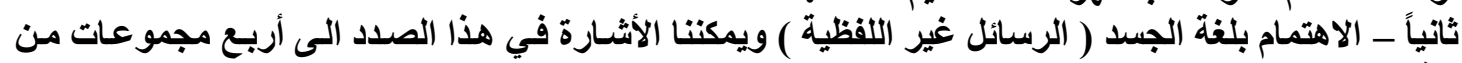
جلول ( ع ع ) الرسائل الايجابية والسلبية غير اللفظية

\begin{tabular}{|c|c|}
\hline رسائل سلبية & رسائل ايجابية \\
\hline الوجه قلق ومتجهم . & عندما يكون الوجه مسترخياً ومحكماً \\
\hline الابتسامة مفقودة ومتجهح . & عندما تكون الابتسامة طبيعية ومريحة \\
\hline تجنب الاتصال بالعين عند الحديث أو الأنصات . & الحفاظ على الاتصال بالعين عند الحديث أو الأنصات للآخرين . \\
\hline حركة الجسد متعجلة ومرفوعة . & حركة الجسد مسترخية ومع ذلك متأنية ومنضبطة \\
\hline
\end{tabular}

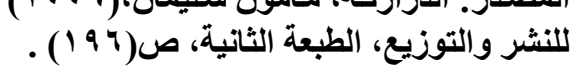

ثالثاً ــ الأصـغاء والتركيز لمعرفة حاجـات الزبـائن مـع تجنب المقاطعة والتلخيص في النهايـة للتأكد مـن فهم

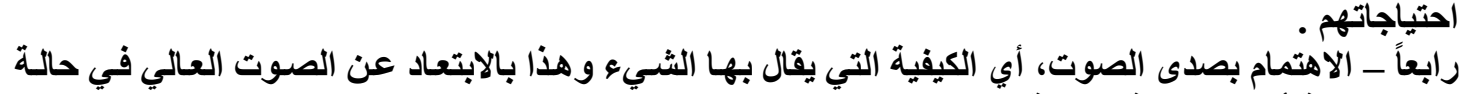

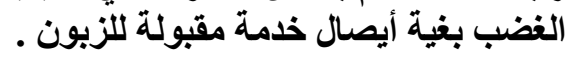

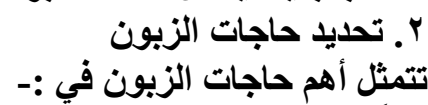

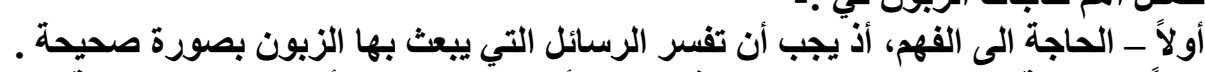

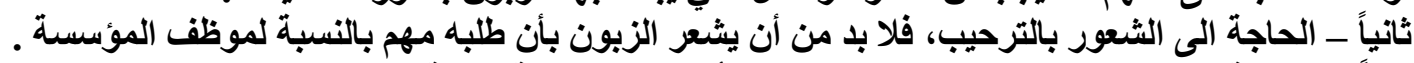

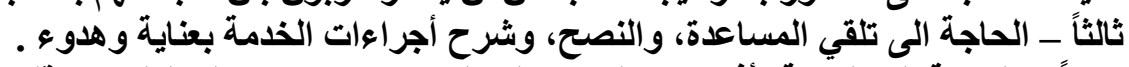

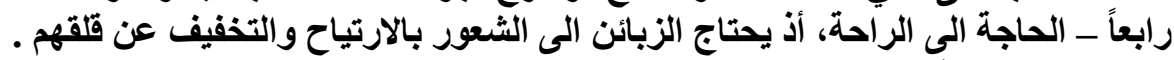

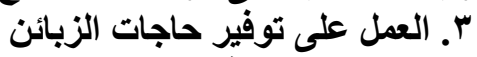

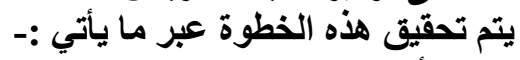

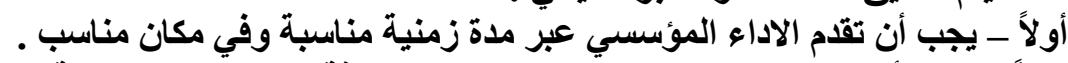

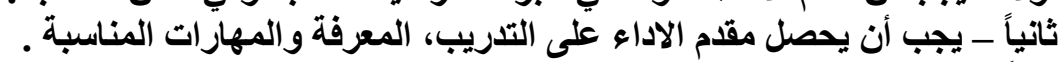

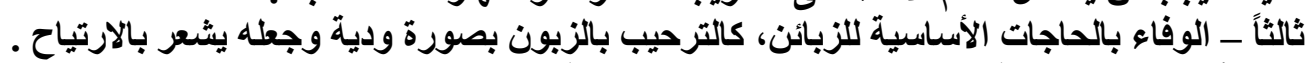

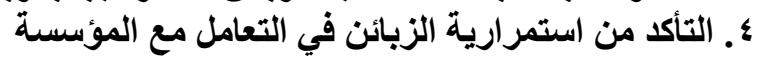

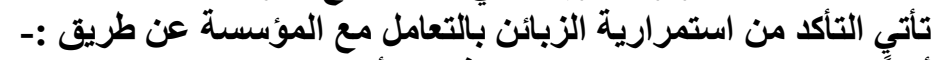

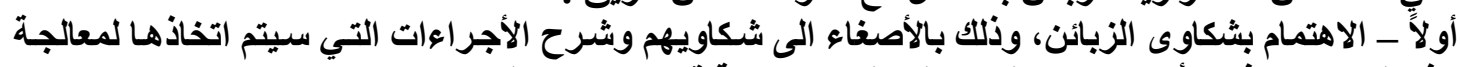

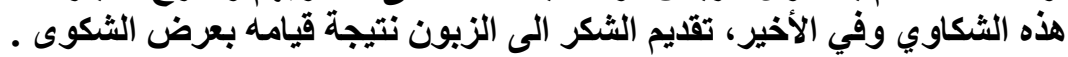


ثانيـاً ـ محاولـة مقدمي الاداء المؤسسـي كسب الزبـائن ذوي الطـابع الصسب عبر المحافظة على هدوئهم

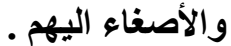
ثالثاً ـ أجراء استطاء الجاعات مستمرة لأراء الزبائن حول مستوى جودة الاداء المؤسسي المقدمة لهم وتقييمهر

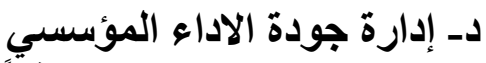

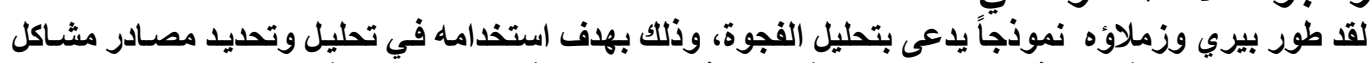

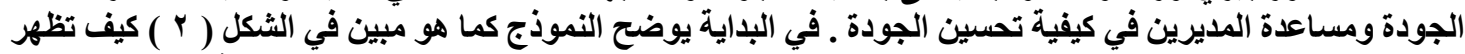

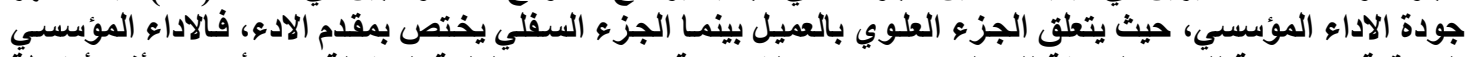

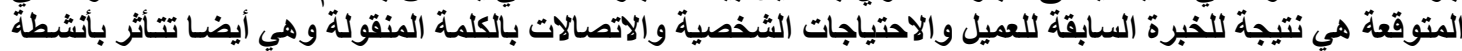

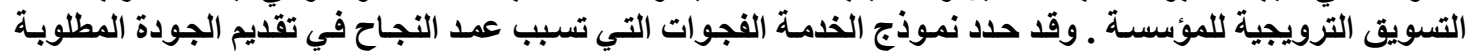

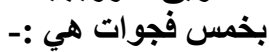

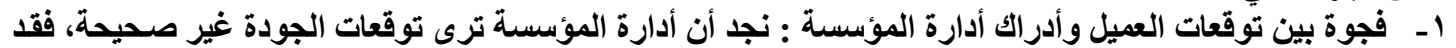

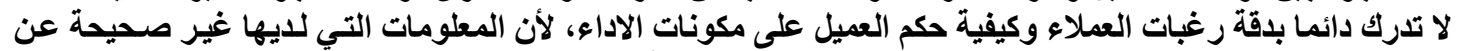

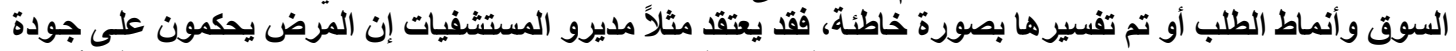

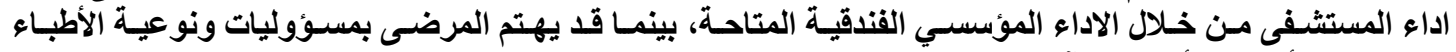

والممرضين أكثر من أي شيء آخر. (Berry, et al., 1985)

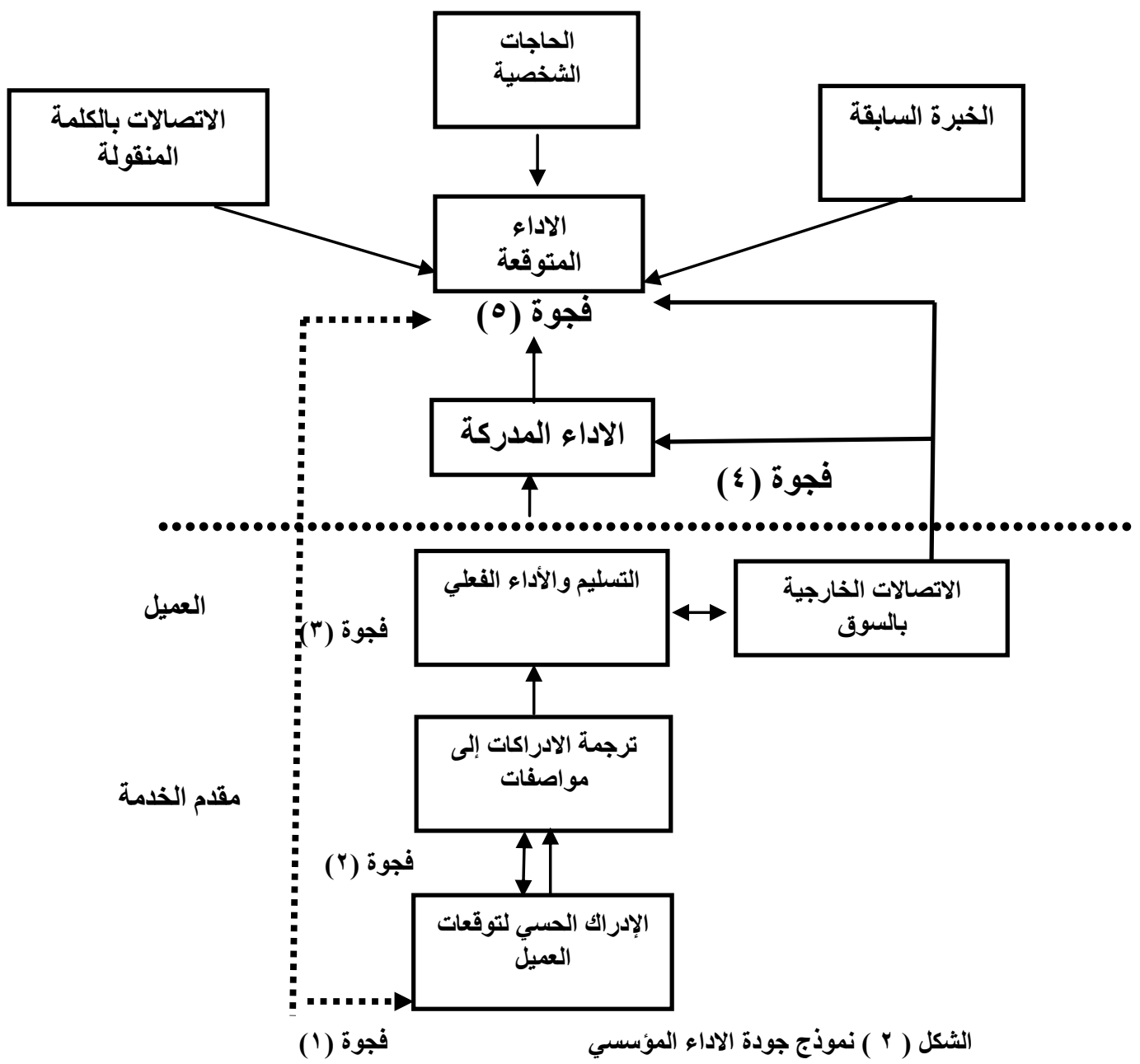

Source : Parauraman, A, Zeithaml, V. \& Berry, L.A Conceptual Model of Service Quality and its Implications for Future , Journal of Marketing Vol . 47 , 1985, pp.40-50 .

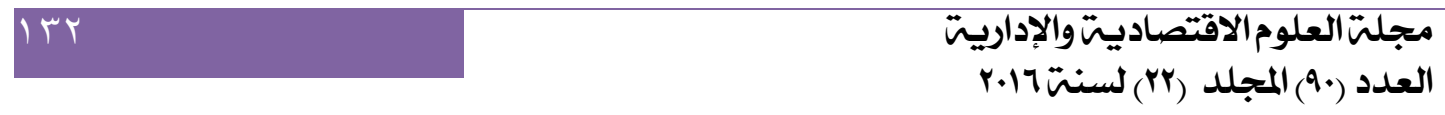




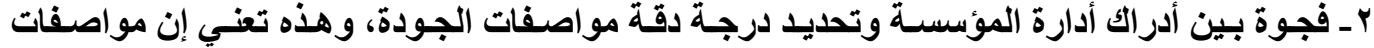

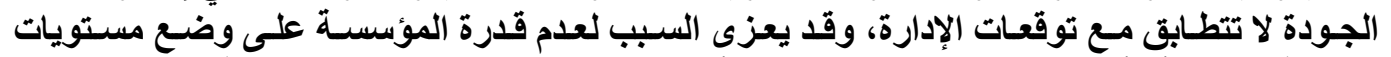

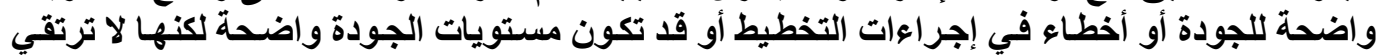

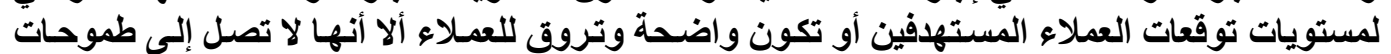

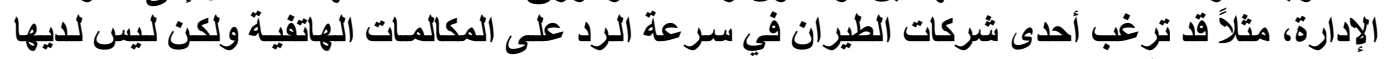

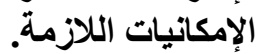

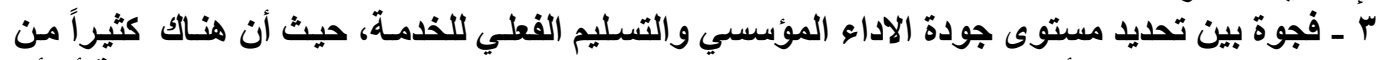

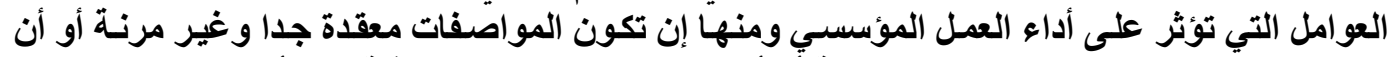

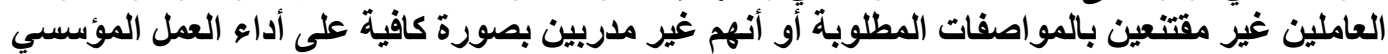

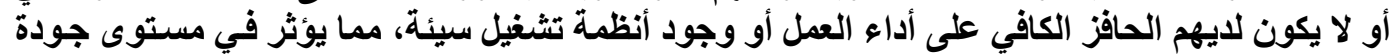

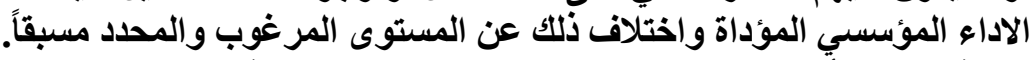

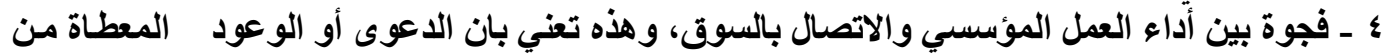

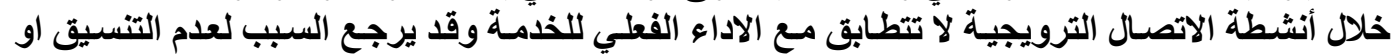

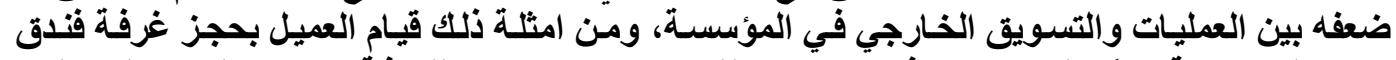

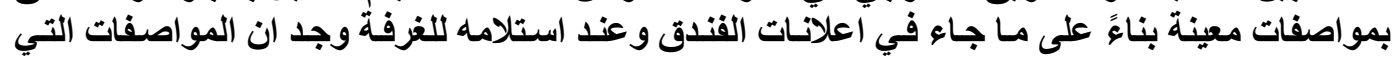

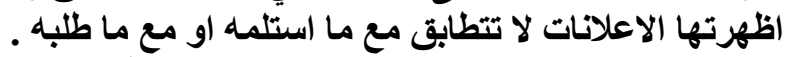

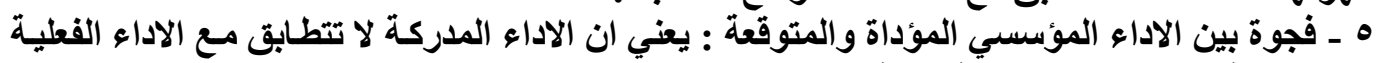

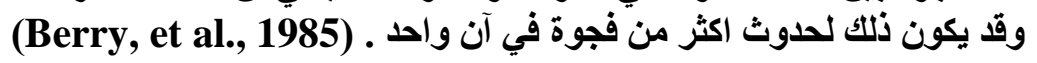

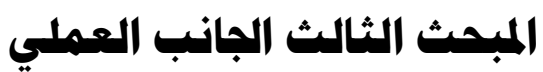

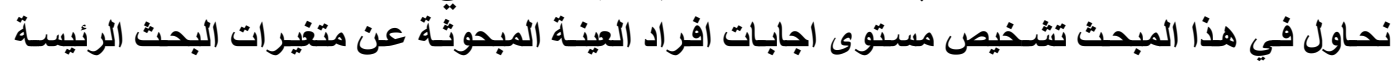

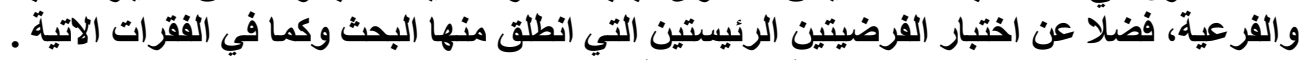

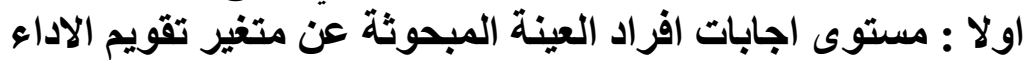

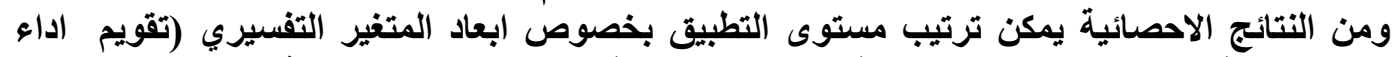

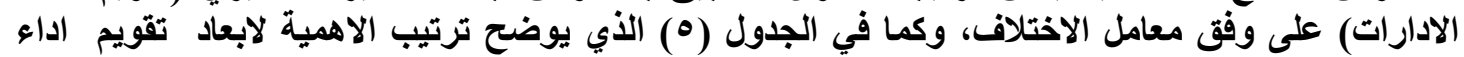

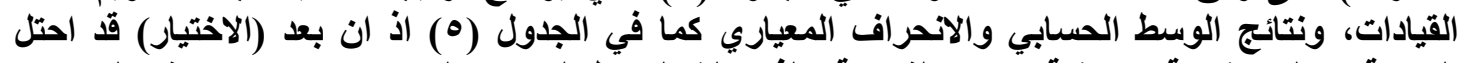

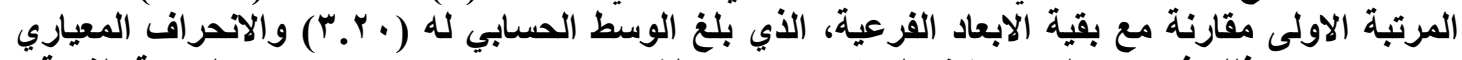

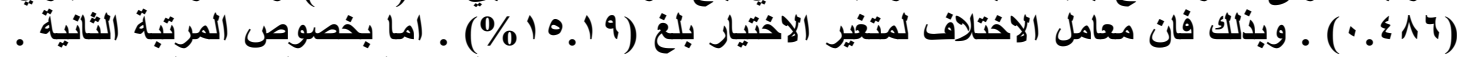

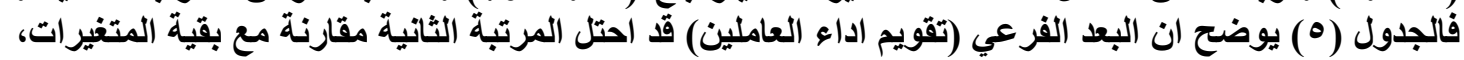

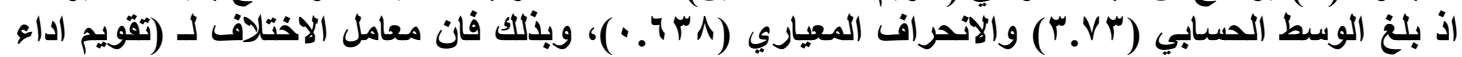

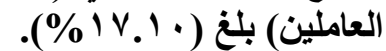

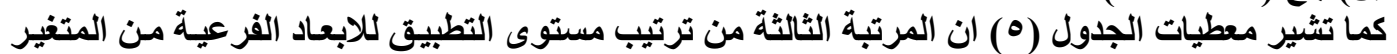

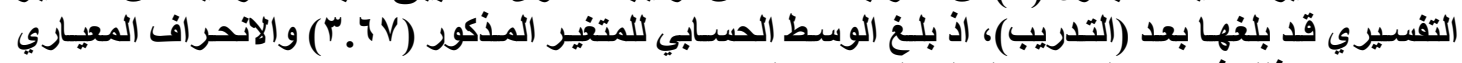

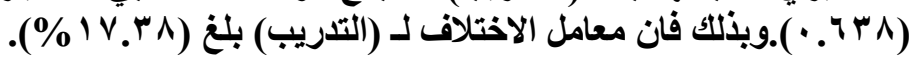

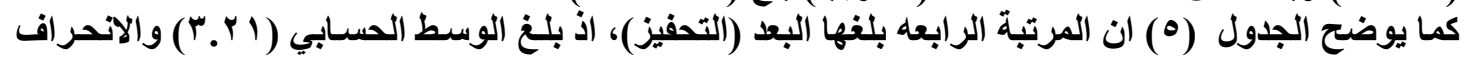

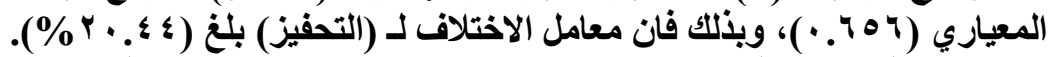

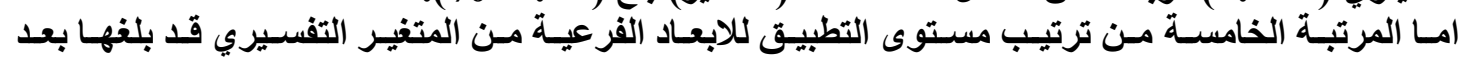

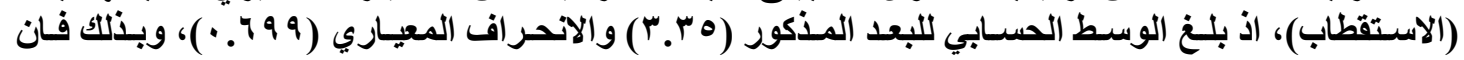

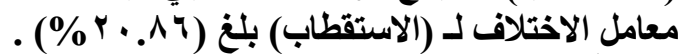

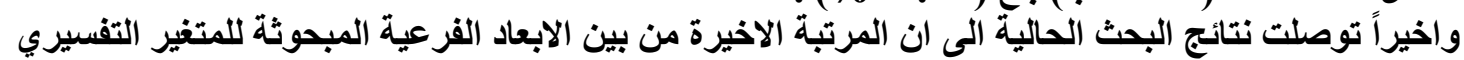

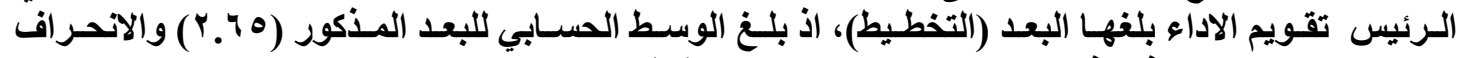

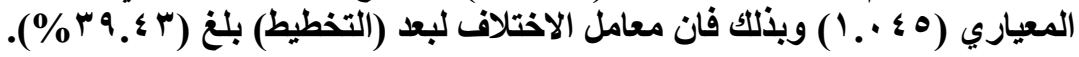




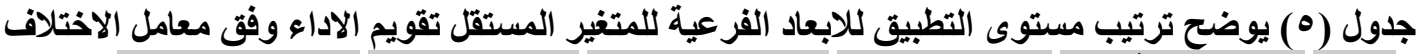

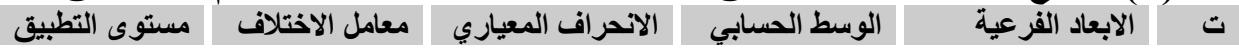

\begin{tabular}{|c|c|c|c|c|c|}
\hline الخامس & $r \cdot . \wedge t$ & .799 & ס.r. & الاستقطاب & $\mathbf{x}^{\prime}$ \\
\hline الثانى & IV.1. & $.9 \mu 1$ & $r . V r$ & تقويم الاداء & $\mathbf{x}^{Y}$ \\
\hline الثالث & IV.rA & ג & r.TV & التدريب & $\mathbf{x}^{\mu}$ \\
\hline الرابع & $r \cdot . \leqslant \xi$ & .907 & r.r & التحفيز & $x^{\varepsilon}$ \\
\hline الاول & 10.19 & ד & r.r. & الاختيار & $x^{0}$ \\
\hline السادس & rq. $\leqslant r$ & $1 . . \leqslant 0$ & $r .19$ & التخطيط & $x^{7}$ \\
\hline
\end{tabular}

ومن النتائج السابقة يتضح ان تقويم الاداء في الوزارة يوفرة معلومات دقيقة من خلابل التل بعد (الاختيـار) .

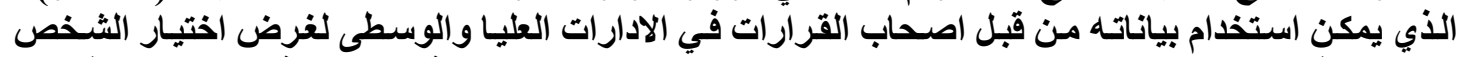

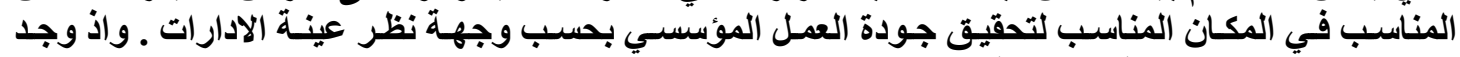

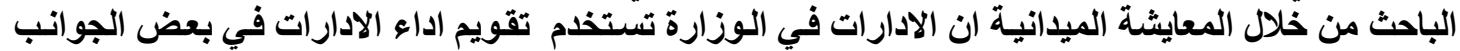

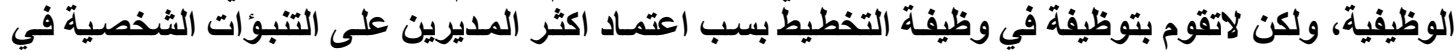

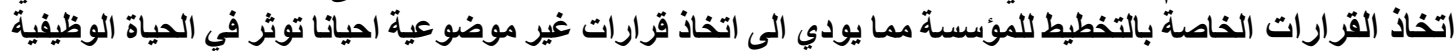
لانموظفين .

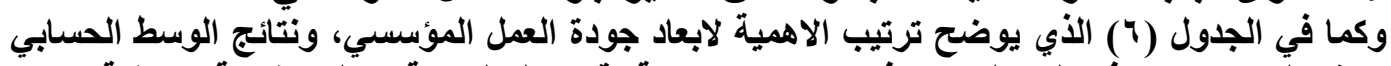

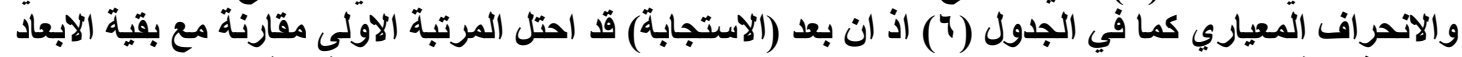

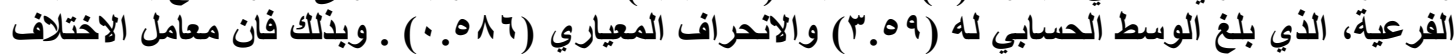

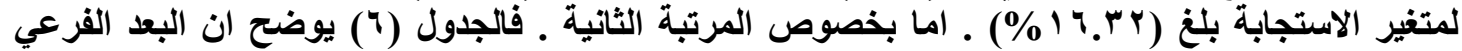

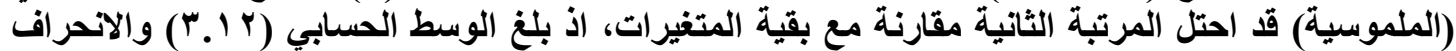

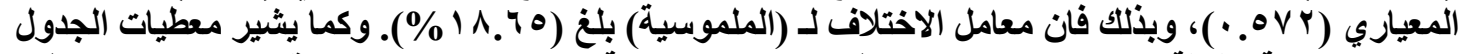

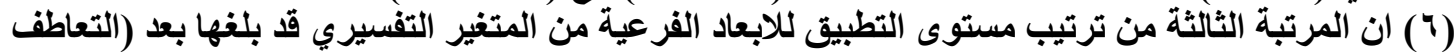

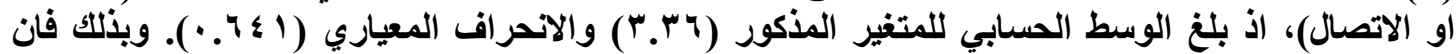

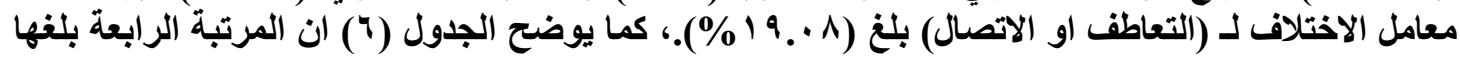

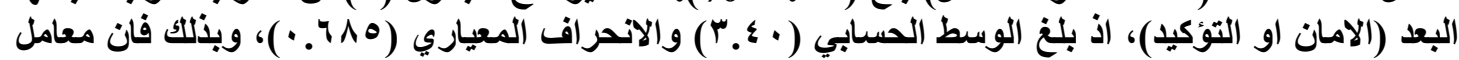

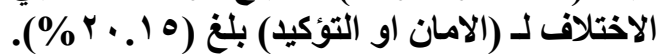
جدول (7) يوضح ترتيب مستوى التطبيق بخصوص الأو الابعاد الفرعية للمتغير الاستجابي جودة العمل المؤسسي

\begin{tabular}{|c|c|c|c|c|c|}
\hline مستوى التطبيق & معامل الاختلاف & الاتحر اف المعياري & الوسط الحسابي & الابعاد الفر عية & ت \\
\hline السادس & $r \leq .9 \varepsilon$ & $\cdot \Lambda \cdot v$ & $r . r r$ & الاعتمادية & $y^{\prime}$ \\
\hline الاول & $19 . r Y$ & .014 & r.०q & الاستجابة & $\mathbf{y}^{\gamma}$ \\
\hline الثاني & 11.70 & $\because O V Y$ & $r .1 r$ & الملموسية & $\mathbf{y}^{r}$ \\
\hline الرابع - ابع & $r \cdot .10$ & $\cdot .710$ & r.६. & الامان او التوكيا & $y \varepsilon$ \\
\hline الثالث & $19 . \cdot 1$ & - . $7 \leqslant 1$ & r.M & التعاطف او الاتصال & $y^{0}$ \\
\hline 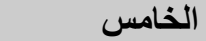 & YY.A & $\cdot V \cdot \varepsilon$ & $r . \cdot \Lambda$ & الاهلية او الجدارة & $y^{\top}$ \\
\hline
\end{tabular}

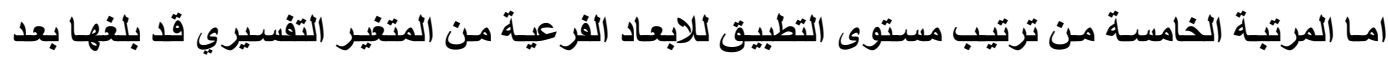

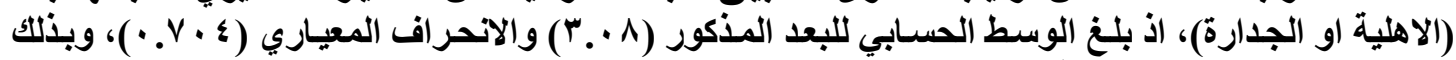

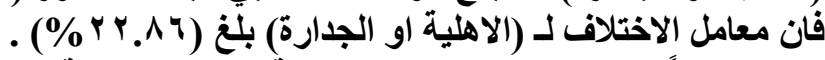

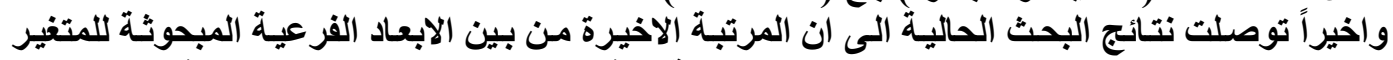

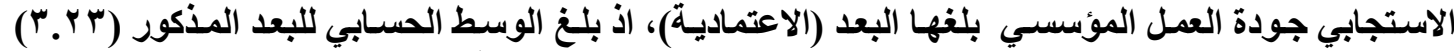

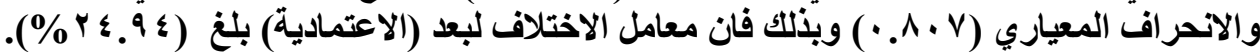




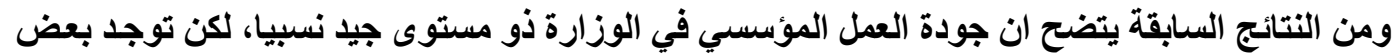

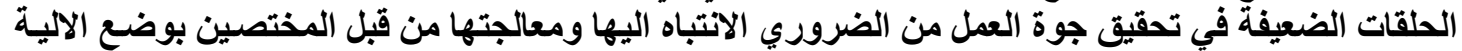

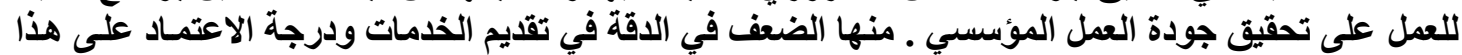

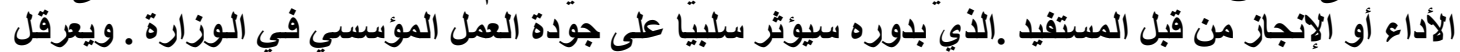

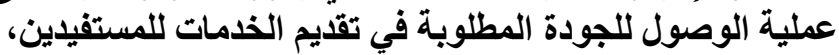

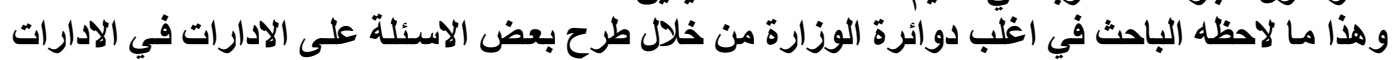

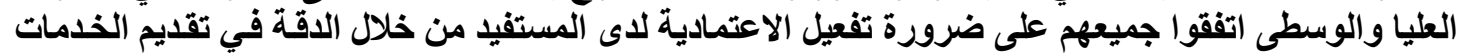

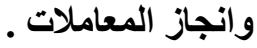
ثالثا : تحليل علاقة الارتباط بين تقويم الاداء وجودة التوة العمل المؤسسي .

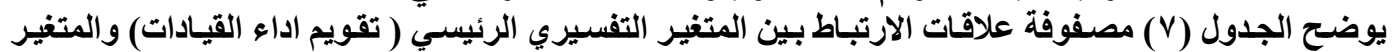

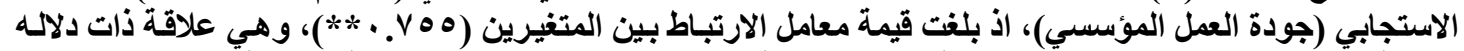

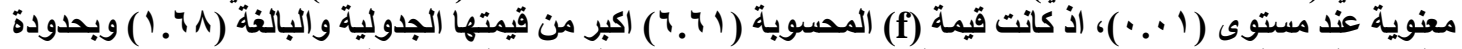

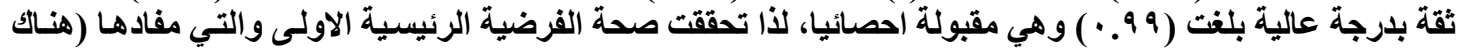

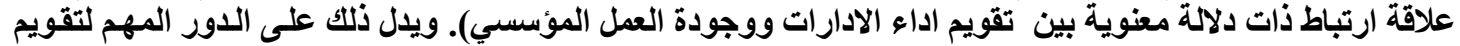

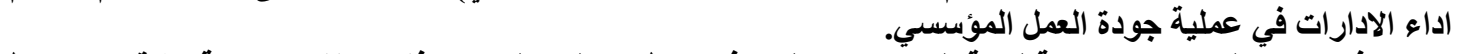

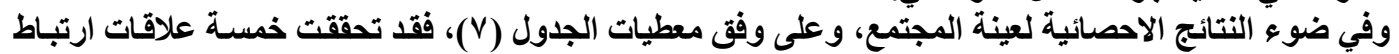

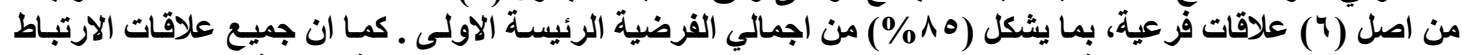

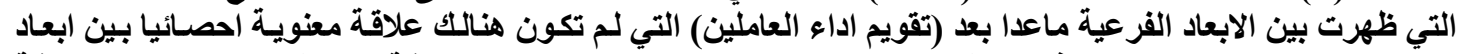

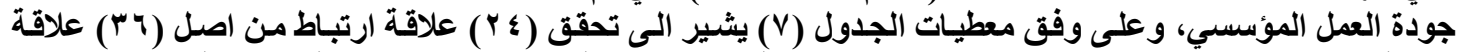

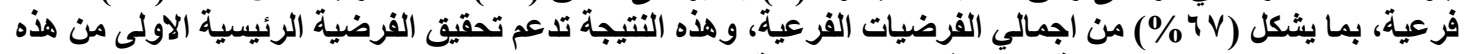

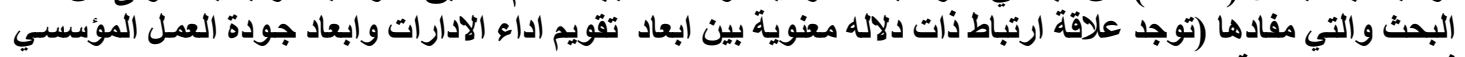

جدول (V) يوضح علاقات الارتباط بين ابعاد تقويم اداء الادارات وابعاد جودة العمل

\begin{tabular}{|c|c|c|c|c|c|c|c|c|c|c|c|c|c|c|}
\hline \multirow{3}{*}{ النسبة \% } & \multirow{3}{*}{ العدد } & \multicolumn{12}{|c|}{ جودة العمل المؤسسي } & \multirow{3}{*}{ 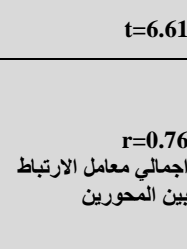 } \\
\hline & & \multicolumn{2}{|c|}{ الاهمية او الجدارة y6 } & \multicolumn{2}{|c|}{ 55 التعـاطف او الاتصــال } & \multicolumn{2}{|c|}{ الامان والتوكيد } & \multicolumn{2}{|c|}{ الملموسية } & \multicolumn{2}{|c|}{ الاستجابة } & \multicolumn{2}{|c|}{ الاعتمادية } & \\
\hline & & $\mathbf{T}$ & $\mathbf{R}$ & $\mathbf{T}$ & $\mathbf{R}$ & $\mathbf{T}$ & $\mathbf{R}$ & $\mathbf{T}$ & $\mathbf{R}$ & $\mathbf{T}$ & $\mathbf{R}$ & $\mathbf{T}$ & $\mathbf{R}$ & \\
\hline$\% 4 v$ & ؛ & V.r & $0.78 * *$ & $1 . \leqslant 0$ & 0.33 & ד. & $0.74 * *$ & ૫. V & $0.72 * *$ & $0 . \wedge 4$ & $0.71^{* * *}$ & $r . r$ & $0.51 *$ & الاستقطاب x1 \\
\hline$\%$. & . & 1.04 & 0.36 & $1.0 \mathrm{~V}$ & 0.29 & $1.7 \mathrm{r}$ & 0.34 & 1.20 & 0.24 & 1.71 & 0.37 & 1.0 & 0.28 & تقويم اداء العاملين x2 \\
\hline$\%$ & $r$ & $r . v \leq$ & $0.54 *$ & 1.47 & 0.29 & $1.0 \mathrm{~V}$ & 0.29 & T.r & 0.34 & ץ. & $0.57^{*}$ & \&.r & $0.57 *$ & x3 التلريب \\
\hline$\% 1 \ldots$ & $\checkmark$ & r.99 & $0.51^{*}$ & $\triangleleft . \wedge$. & $0.76 * *$ & $r . v r$ & $0.54 *$ & r.or & $0.52 *$ & 17.4 & $0.79 * *$ & 0.94 & $0.71 * *$ & التحفيز x4 \\
\hline$\% \wedge r$ & 。 & $\varepsilon . \wedge v$ & $0.57 *$ & ๕.14 & $0.58 *$ & \&.r & $0.59^{*}$ & $1.0 \mathrm{~V}$ & 0.31 & $\checkmark . \wedge \wedge$ & $* * 0.76$ & $.7 \mathrm{~V}$ & $0.74 * *$ & الاختيار55 \\
\hline$\% 1 \ldots$ & $\checkmark$ & $1 . .09$ & $0.87 * *$ & A.\& & $0.82 * *$ & $v .04$ & $0.79 * *$ & $\wedge . \wedge \wedge$ & $0.84 * *$ & $1 \cdot !$ & $0.87^{* * *}$ & A.v & $0.83^{* *}$ & التخطيط x6 \\
\hline$\%$ iv & $r \varepsilon$ & & & & & & الاجمالـــ & & & & & $\because$ & - ل مستوى & 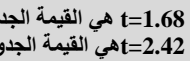 \\
\hline
\end{tabular}




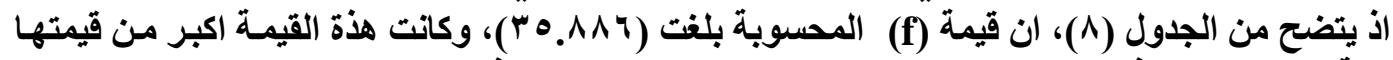

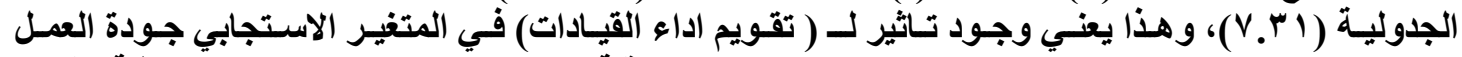

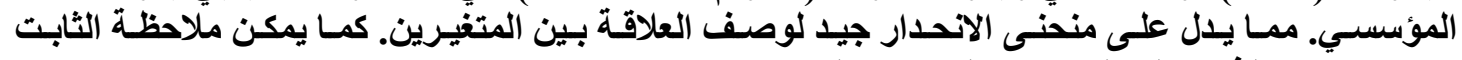
(a= 0.476)

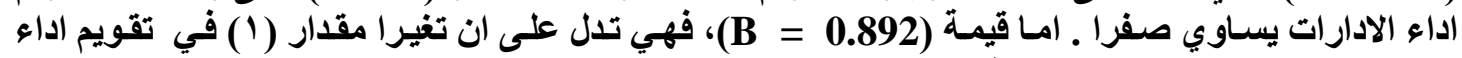

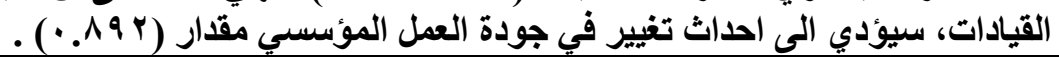

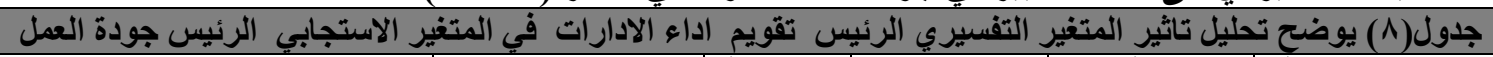

\begin{tabular}{|c|c|c|c|c|c|}
\hline الانموذج & مجموع المربعات & لدرجية & متوسيـــــــ & قالميـــــــة (F) & مستوى المعنوية \\
\hline الاتحدار ( الجزء (المفسر) & 7.1 .1 & 1 & $7.1 \cdot 1$ & ro.A14 & $\because \cdots$ \\
\hline الباقي ( الجزء غير المفسر ) & $0 . \leqslant \leqslant T$ & rr & $.1 \mathrm{~V}$. & & \\
\hline مجموع الانحرافات & $11.0 \leq \leqslant$ & $r r$ & & & \\
\hline$n=34$ & $R^{2}=0.570$ & \multirow{2}{*}{\multicolumn{4}{|c|}{ 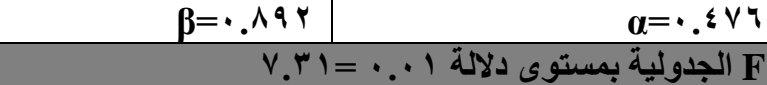 }} \\
\hline 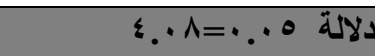 & F الجدولية بمس F & & & & \\
\hline
\end{tabular}

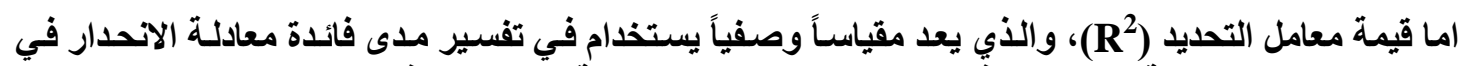

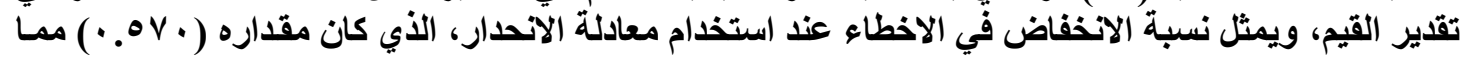

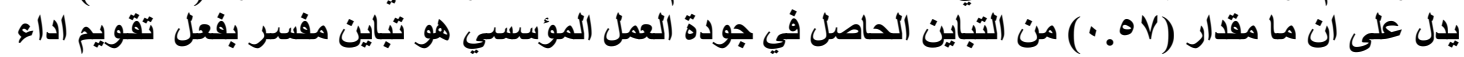

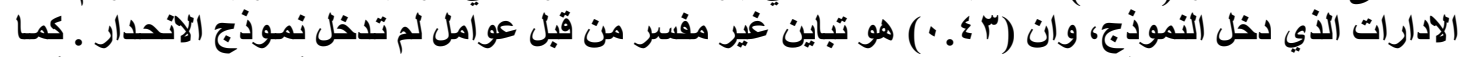

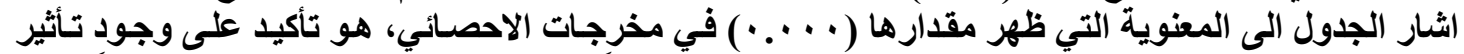

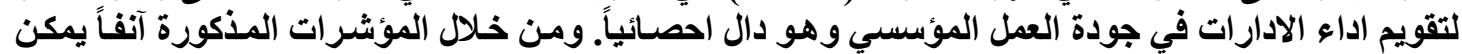

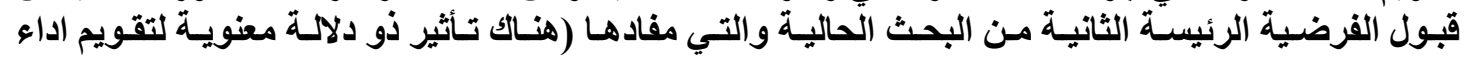

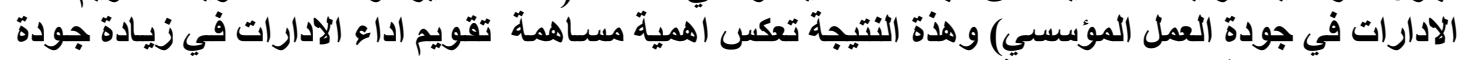

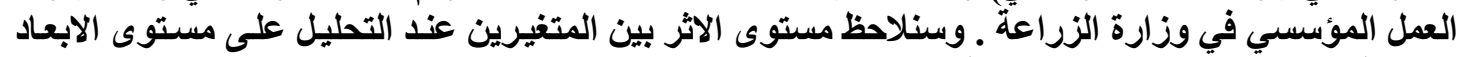

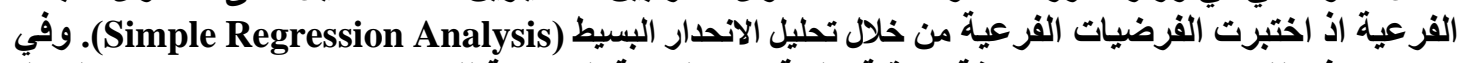

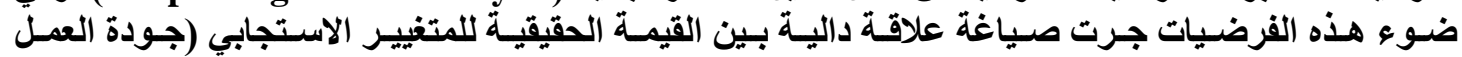

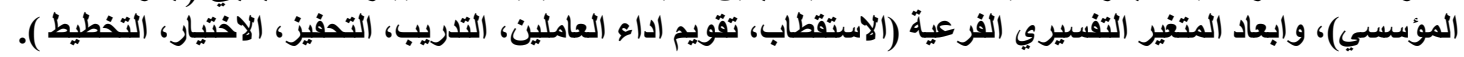




\section{المبحث الرابع / الاستنتاجات والتوصيات}

اولا : الاستنتتاجات

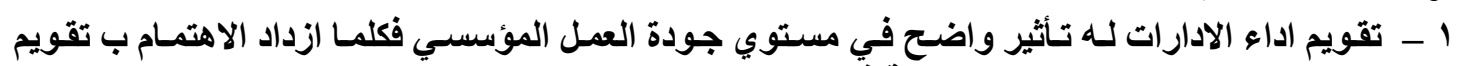

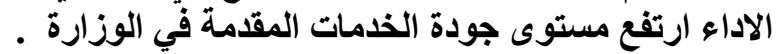

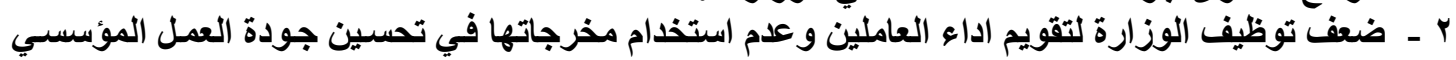
وتقديم الخدمات للمراجعين .

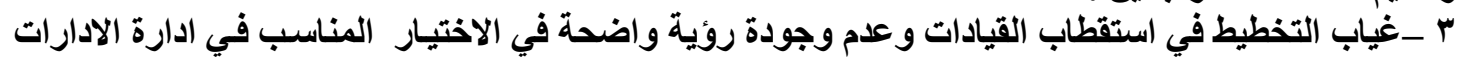

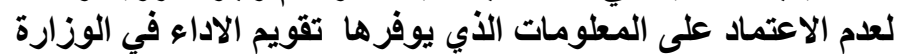

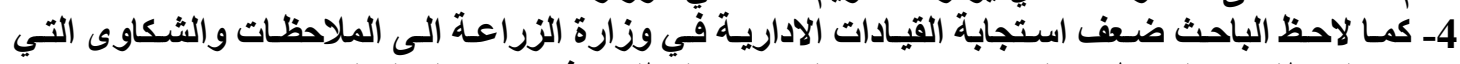

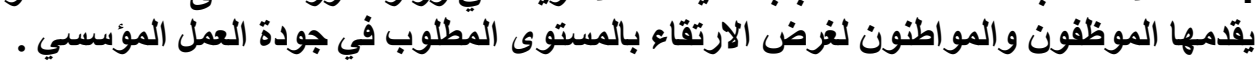

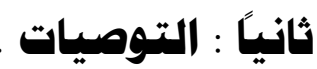

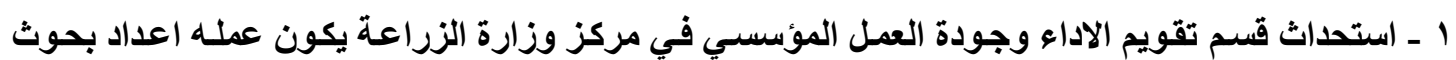

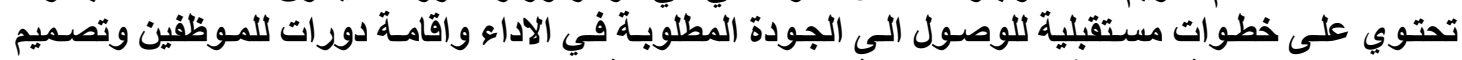

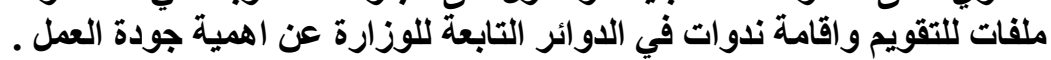

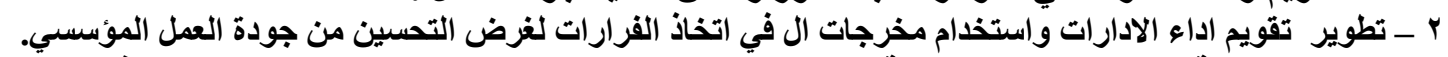

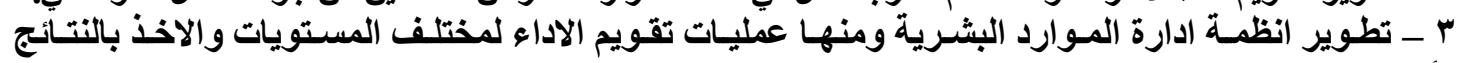

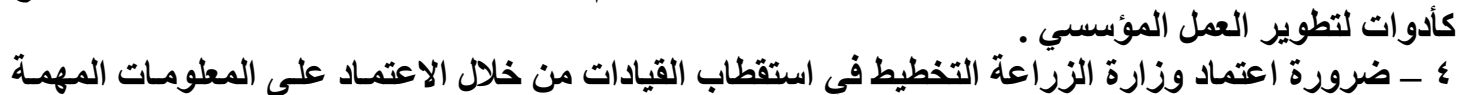

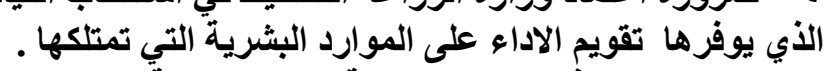

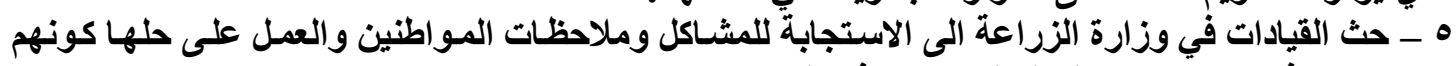

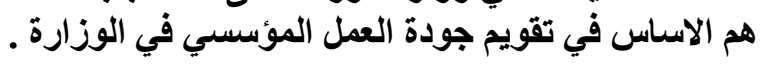

\section{المادر}

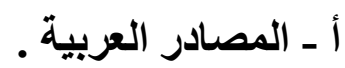

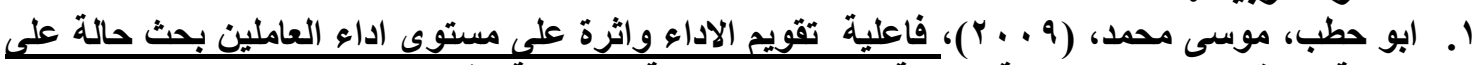

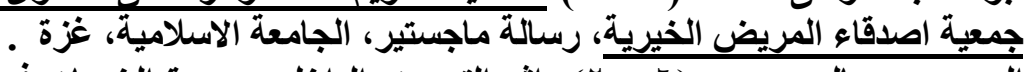

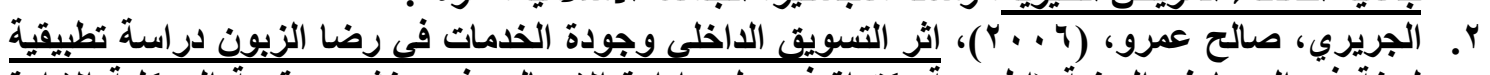

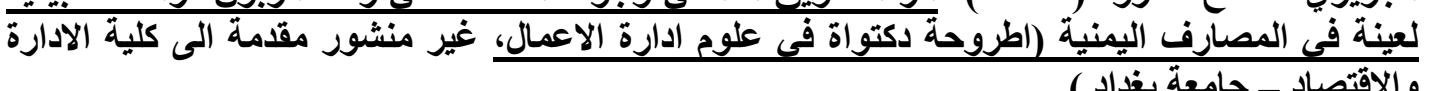

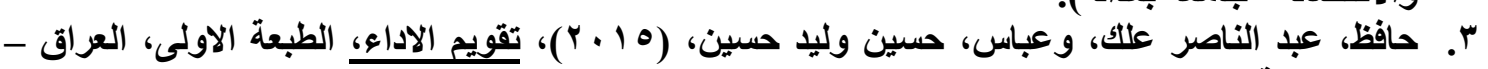

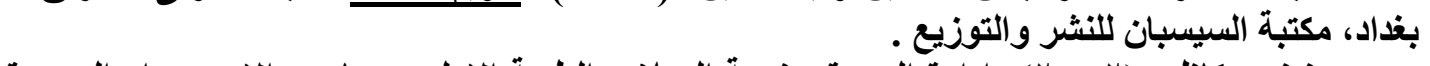

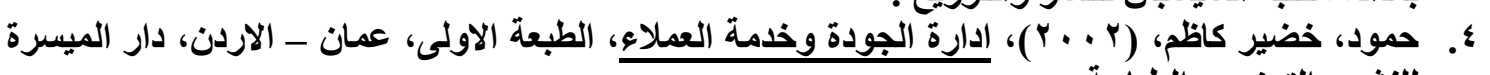

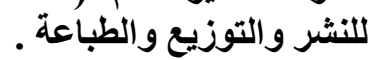

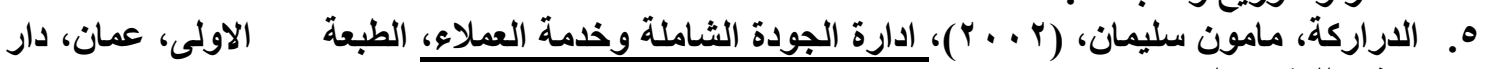

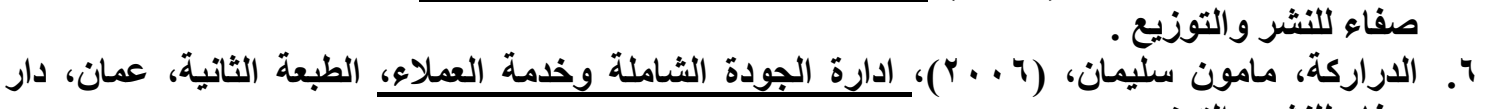
صفاء للنشر والتوزيع.

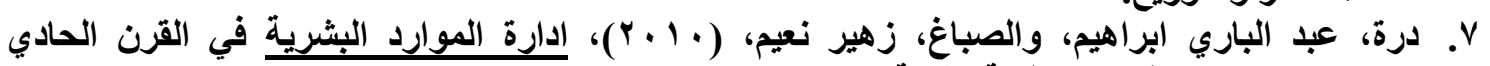

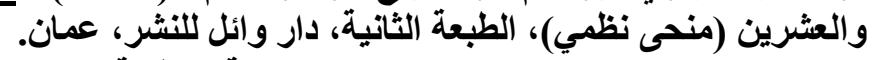

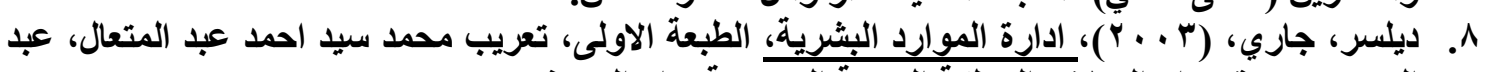

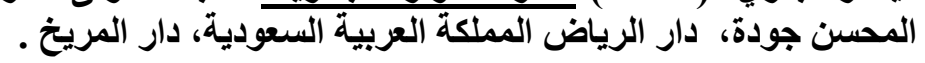

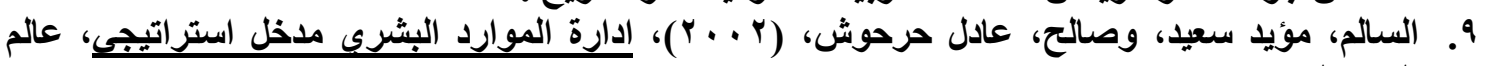

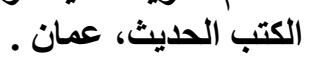




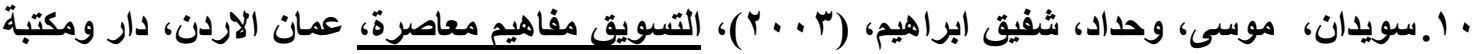

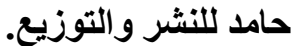

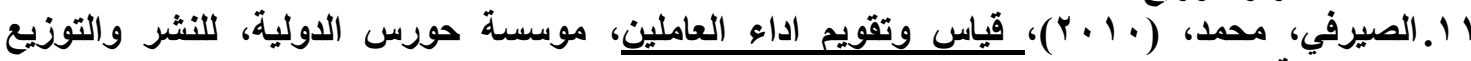

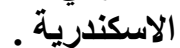

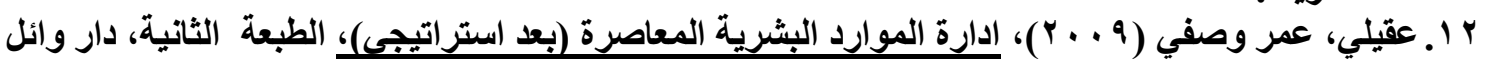

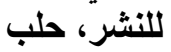

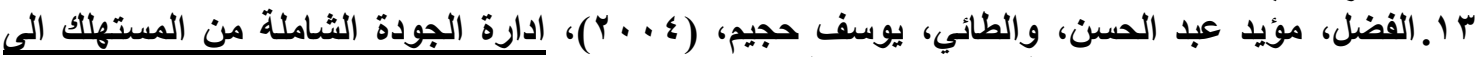

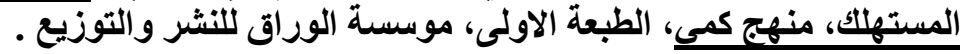

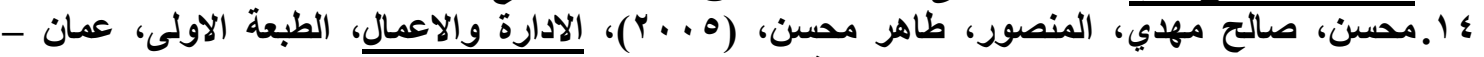

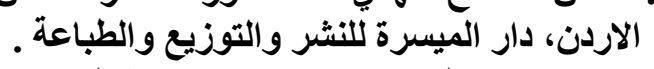

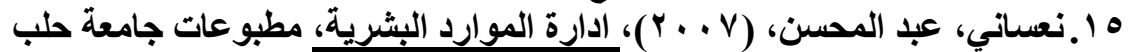

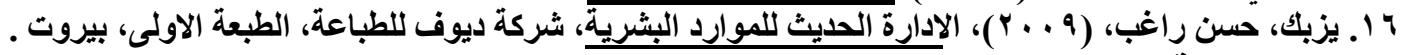

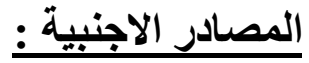

17 Ahmed, De.Abedl Moneim and Dablan, Duaai (2007), the Role of the Appraisal System in Developing Employees Performing The case of Oman Insurance, e-TQM, College

18 Beardwell Julie and Clydon Tim, (2010) Human Resource Management, $6^{\text {th }}$ ed., prentice hall, London.

19 Bohlander, George and Snell Scott (2004), Human Resource Management, Prentice Hall, New Jersey

20 Denisi, Angelo S. and Griffin, Richy E (2001), Human Resource Management, Houghton Miffin Company, Boston.

21 Dessler Cary, (2010), Human Resource Management, $12^{\text {th }}$ ed., Prentice - Hall, New Jersey

22 Gawankar, Abhijeel S. (2006), Performance Appraisal System at Lilavati Hospital and Research Center University of Pure, MBA.

23 Jafari, Mostafa and Bourouni, Atieh and Amiri, Roozbeh,(2009), A New Framework for Selection of the Best Performance Appraisal Method, European journal of social sciences. Vol7, No.3.

24 Lezzoni, L., and Davis ,R., (2003), Quality Dimensions that Most Internal Medicine.

25 Noe, Raymond A., Hollenbeck John R., Gerhart Barrt, and Wright Patrick M.m (2011), Fundamental of Human Resource Management, $4^{\text {th }}$ ed., McGraw - Hill Irwin, New York.

26 Parasuraman A., Zeithmal, V. and Berry, L.L (1985), A Conceptual Model od Service Quality and its Implications for Future, Journal of Marketing 49,(fall).

27 Sani , Abdulkadir Dsanlami (2012), Strategic Human Resources Management and Organiz Performance in Nigerian insurance industry: the impact of Organizational Climat, business intelligence journal- Vol.5 No.

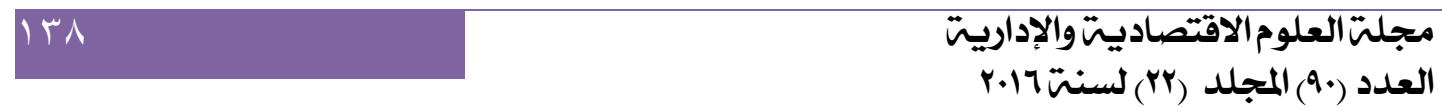




\section{Performance Evaluation for Higher and Medium Leadership in Institutional Work Quality.}

$\underline{\text { Abstract: }}$

This Research aims to define role of the system of evaluating the performance for higher leadership in determining the level of institutional work quality in the Ministry of Agriculture, by measuring system efficiency of evaluating the performance for higher leadership and its effect in institutional work quality, the searcher reached through the theoretical framing and involved studies to build default plan define the relation between Research variables formed from system of evaluating leadership performance as independent variable contains six subsidiary dimensions: (Polarization, evaluating the performance of personnel, training, motivation, selection, planning ) and quality of institutional work as independent variable contains six subsidiary dimensions (Reliability, responsiveness, tangibility, security or confirmation, sympathy or contact, civil or merit) these variables reacted to form the frame of Research, the Research community consists of managers of managerial positions in the level of high and medium levels in the Ministry of Agriculture. We used technique of comprehensive inventory where the Research was applied to all members of the community, which contains general managers and their assistants and heads of departments in the ministry administrations who numbered (34) institutional, and the response rate was $(\mathbf{1 0 0 \%})$, The questionnaire had used as essential tool in collecting information and data, and (SPSS) program, the Research came out with set of recommendations based on the conclusions that I reached that include the need of the ministry to attach importance to evaluate the performance of more leadership and rely on their outputs in the process of improving the quality of institutional work system, to gain process efficiency, accuracy and objectivity in raising the level of quality of work.

Key Word/ performance evaluation- Quality- quality of institutional workleadership performance. 